\title{
PROCEDIMIENTOS PARACONCURSALES: ¿REGULACIÓN ADMINISTRATIVA O JUDICIAL DE LOS CONCURSOS?
}

\author{
Maria Isabel Candelario Macías*
}

\begin{abstract}
Sumario: I.- Nota Introductoria. II.- Breve Reseña sobre la regulación concursal española. II.1.- Antecedente directo (pero con matices) de la Ley Concursal española respecto al Reglamento (CE) 1346/2000, sobre procedimiento de insolvencia comunitaria. II. 2.- Una válvula de escape: Unidad procedimental versus Disposición Adicional $2^{\mathrm{a}}$ LCon. II. 3.- Muestras (Leyes) de difícil naturaleza entre lo concursal y lo paraconcursal. III.- La disciplina de los procedimientos paraconcursales. III. 1.- Perspectiva comparada de los procedimientos paraconcursales. IV.- Ejemplos paradigmáticos de coexistencia netamente diferenciada de procedimiento general y procedimientos paraconcursales (Italia e Inglaterra/ Argentina). V.- Conclusiones. VI.- Bibliografía destacada.
\end{abstract}

- Resumen: La presente investigación tiene como objetivo abordar algunas cuestiones relativas a los procedimientos concursales, en su regulación administrativa y judicial. Coexisten en muchas leyes, por un lado, el procedimiento judicial y, por otro lado, los procedimientos llamados "paraconcursales" de tez administrativa notablemente. Es precisamente en esta terminología y sus consecuencias, que se centra este artículo, para extraer los puntos comunes y divergentes, que nos ayude a explicar por qué el uso de "procedimientos paraconcursales" y si ayuda o no el examen y resolución de problemas inherentes a la insolvencia.

- Palabras-clave: procedimientos paraconcursales; regulación administrativa y judicial; quiebra; insolvencia.

- Abstract: This study examines some aspects of tendering procedures in its administrative and judicial regulation. There are many laws which coexist prosecution and, on the other hand, the procedures called "paraconcursais", that is a noticeably complexion kind of administrative procedure. This article focuses precisely this terminology and its consequences, to extract common denominators as well as divergent, to help us to explain why the use of "procedures paraconcursais" and whether or not he enjoys the competition and problem solving inherent to insolvency.

- Keywords: tendering procedures; administrative and judicial regulation; bankruptcy; insolvency.

\section{I.- Nota Introductoria}

Vivimos en un mundo donde las economías y los mercados se hallan globalizados y se persiguen valores como la cooperación, competitividad, innovación, transparencia y responsabilidad social. Pero también resulta cierto que en este escenario surge y se revela el fenómeno de la crisis económica y financiera, que hay que intentar apartar y paliar del mejor modo posible. Cabalmente, esa crisis económica se manifiesta con diferentes aristas, siendo quizá la falta de crédito (ausencia de confianza) la que más menoscabos o perjuicios ocasiona. La crisis económica busca remedios para solventar ese estado de cosas, -que suele ser más o menos pasajero-, y el Ordenamiento jurídico no puede -ni

*Profesora Titular de Derecho Mercantil em la UNIVERSIDAD CARLOS III DE MADRID, ESPAÑA 
debe- permanecer alejado e indiferente ante tal fenómeno, siendo el Derecho de la empresa en crisis, -o bajo otra terminología- de bancarrota, concursal, quiebra o suspensión de pagos un instrumento certero para atajar dicha situación. Si bien es verdad que -en muchas ocasiones- el Derecho concursal no es la medicina o panacea para resolver per se las situaciones de dificultades económicas o crisis empresariales, incorporándose otra serie de mecanismos destinados a solucionar la situación y dónde la intervención estatal ${ }^{1}$ tiene un papel protagonista.

Ante este contexto de actuación y mediante la presente contribución lo perseguido no es exponer qué países tienen una regulación de tenor administrativo (ejemplos de la legislación de Colombia o Perú) de sus procedimientos concursales y cuáles un procedimiento judicializado (España). No obstante, responderemos al interrogante que da título a esta presentación, deteniéndonos sólo en alguno de sus aspectos, toda vez que son muchas las legislaciones donde cohabitan, por un lado, el procedimiento judicial y unido a éste, de otro, unos procedimientos denominados "paraconcursal/es" de cariz marcadamente administrativo. Precisamente, sobre esta terminología y sus consecuencias es dónde nos centramos para extraer denominadores comunes, así como divergentes que nos ayuden a explicar el por qué del empleo de "procedimientos paraconcursales" y si ello beneficia o no al concurso y la resolución de los problemas inherentes a la insolvencia.

Adviértase que el trabajo se confecciona desde la óptica que nos proporciona la legislación vigente en el Ordenamiento jurídico español, y de ahí que se parta de la regulación concursal en España, y nos cuestionemos si esta legislación resulta satisfactoria y suficiente para solventar la crisis económica o ha sido preciso el dictar otras leyes complementarias -y sí las mismas entran dentro del paraguas- de la intervención estatal. Una vez observada la legislación concursal española, hemos de comentar qué se entienda por procedimiento paraconcursal y cuál es su desarrollo, para posteriormente apreciar una serie de ejemplos

\footnotetext{
${ }^{1}$ Véase mi artículo: "Algunas consideraciones sobre la intervención estatal en el derecho concursal", en Internet, http://noticias.juridicas.com/articulos/50-Derecho\%20Mercantil/199911-isable.html, noviembre de 1999, donde ya apuntaba que "en el Derecho español la intervención estatal aparece implícita a través del art.38 de la Ce. en donde la libertad de empresa como la libre competencia se han de ejercitar de acuerdo con las exigencias de la economía en general. Sin embargo, nótese, la acusada ambigüedad de este mandato constitucional. Por un lado, nos encontramos ante una autorización constitucional para legitimar una política económica de intervención de la actividad empresarial, al fijar las condiciones o modalidades en razón de las "exigencias de la economía general" en cuanto que estas no pueden ser transgredidas o perjudicadas en el ejercicio de la actividad empresarial. Y por otro lado, el impulso de la libertad de empresa bajo un sistema de libre competencia que conlleva la libertad de cesación de la actividad empresarial por razones de incompetencia e inadaptación al mercado. Si bien la intervención del Estado viene justificada por la defensa del interés general y el mantenimiento de la empresa, y así proteger a los trabajadores, esto no encuentra oposición por parte de los sindicatos, pero los medios empresariales sí ven un intervencionismo peligroso que llevaría al Estado a sustituir a los dirigentes y a los capitales de terceros a asumir riesgos, y todo ello, favoreciendo con ayudas especiales a las empresas que declinan en detrimento de las empresas prósperas o capacitadas".
} 
paradigmáticos en torno a los procedimientos paraconcursales y, finalmente, extraer y manifestar algunas conclusiones sobre el particular.

\section{II.- Breve Reseña sobre la regulación concursal española.}

En lo que atañe al Ordenamiento jurídico español, hemos de partir del planteamiento que la Ley concursal ${ }^{2}$ número 22/2003, de 9 de julio $\left(B O E \mathrm{~N}^{\circ} .164,10\right.$ de julio), (en adelante LCon), se acompaña de la Ley Orgánica para la Reforma Concursal 8/2003, estableciendo los principios de unidad legal, de disciplina y de sistema. El principio de unidad legal ${ }^{3}$ ordena en un único cuerpo legal toda la legislación sustantiva y procesal demandada por la realidad concursal, corrigiendo la situación anterior contemplada en el Código de Comercio de 1885 y, a la par, por la legislación especial de la suspensión de pagos de 1922, particularmente. Por su lado, el principio de unidad de disciplina, origina que, frente a la tradicional preferencia de nuestro Derecho por distinguir diversos institutos concursales en adecuación al tipo de persona o entidad afectada o de la clase de insolvencia, se opta por perfilar una única institución concursal, que se aplicará a todo tipo de insolvencias y afectados. Y, por último, la unidad de sistema se sustenta en concentrar en un único texto legal la materia concursal con exclusión de que se aprecien determinadas especialidades.

Si acudimos al tenor literal de su Exposición de Motivos, en su apartado II,

\footnotetext{
${ }^{2}$ Una de las principales modificaciones habidas sobre esta norma lo constituye el Real Decreto-ley $3 / 2009$, de 27 de marzo, de medidas urgentes en materia tributaria, financiera y concursal ante la evolución de la situación económica (BOE N ${ }^{\circ}$. 78, de 31 de marzo de 2009).

${ }^{3}$ Manifiesta PULGAR EZQUERRA, J."El contenido dilatorio y remisorio del convenio concursal y las ayudas de Estado". No.1. Revista de Derecho Concursal y Paraconcursal, 2004. p.133, "se introduce un nuevo marco institucional concursal configurado bajo el principio de unidad en un triple ámbito, legal, procedimental y subjetivo. Sobre la base de este planteamiento -por el que desde hacía ya algún tiempo se había optado en el marco del Derecho Comparado, pero absolutamente novedoso en nuestro Derecho, tradicionalmente caracterizado por la pluralidad y dispersión normativas-, se configura el denominado concurso de acreedores, al que puede quedar sometido el deudor común con independencia de su condición empresarial (unidad subjetiva), ...cuyos aspectos sustantivos e internacionales se encuentran regulados en la Ley 22/2003, de 9 de julio (unidad legal)...". Por su lado, puntualizan: LÓPEZ-BARAJAS PEREA, I. y GÓMEZ-SANCHA TRUEBA, I."Especialidades del concurso de las entidades financieras tras la nueva Ley Concursal". $\mathrm{N}^{\circ} .254$. Revista de DerechoMercantil, 2004. pp.1545 y 1550, "nace con una finalidad homogeneizadora y uniformadora del tratamiento de la crisis de todos los sujetos (sean persona físicas o jurídicas, comerciantes o no), plantea como primer interrogante el de si las medidas que conforman el régimen jurídico de las crisis económicas de las entidades financieras y de determinadas operaciones financieras sujetas a normas concursales especiales han sobrevivido a la Reforma concursal o, en qué medida habrán de verse afectadas por ella (...)". Ídem precisa en p.1573, "la expresión que se utiliza en la Exposición de Motivos resulta imprecisa, en la medida en que la legislación que se mantiene no es sólo la aplicable a las 'entidades de crédito', a las aseguradoras y a las operaciones relativas a los sistemas de pagos y de compensación de valores o instrumentos financieros derivados, sino también la que afecta a las empresas de servicios de inversión, así como la que regula determinadas operaciones financieras, como los acuerdos de compensación realizados en el marco de una operación financiera, conocidos como netting, o las cesiones de crédito que sirven de base a la técnica conocida como factoring".
} 
expresamente se destaca: "la Ley opta por los principios de unidad legal, de disciplina y de sistema. La regulación es un solo texto legal ...es una opción de política legislativa que venía ya determinada por la Ley 1/2000, de Enjuiciamiento Civil...La superación de la diversidad de instituciones concursales para comerciantes y no comerciantes...viene determinada por la tendencia a simplificar el procedimiento, sin que ello suponga ignorar determinadas especiales del concurso de empresarios sometidos a un estatuto propio (llevanza obligatoria de contabilidad, inscripción en el Registro Mercantil) y de la existencia en la masa activa de unidades productivas de bienes o de servicios, especialidades que son tenidas en cuenta a lo largo de la regulación del concurso, desde su solicitud hasta su solución mediante convenio o liquidación. La unidad de procedimiento de concurso se consigue en virtud de la flexibilidad de que la ley lo dota, que permite su adecuación a diversas situaciones y soluciones...".

Se infiere de la justificación del legislador: de un lado, la prevalencia del principio de unidad ${ }^{4}$ que informa al ordenamiento concursal ilustrado en la Ley general 22/2003, y de otro, -como complemento de lo anterior-, la vigencia de las especialidades (ex Disposición Adicional $2^{a}$ de la LCon), que manifiestan que concretos sujetos, entre estos, las entidades de seguros y sus operaciones han de someterse en particulares situaciones a lo que se considera por el régimen concursal como legislación especial.

En efecto, la entrada en vigor de la LCon, plantea importantes repercusiones en la vida económico-empresarial ${ }^{5}$. Ahora bien, no descuidamos el dato -también consabido- que el tratamiento y alcance del problema de la insolvencia y de qué modo incide en la actividad empresarial adopta diversos derroteros, de un lado, nos encontramos con el camino que nosotros intentamos recorrer y analizar cómo es la resolución por el cauce legal, esto es, solucionar la insolvencia empresarial trámite su declaración judicial en un procedimiento concursal; pero también existen otros senderos como son la venta, fusión u otro tipo de medidas, entre estas, la liquidación de forma privada ${ }^{6}$, todas ellas destinadas a superar la insolvencia y salvar a la empresa y, en definitiva, sus créditos, que también se encuadrarían dentro del arco de actuación que supone el riesgo-insolvencia para el crédito ${ }^{7}$. En similar línea de argumentación, tampoco se nos escapa que junto al procedimiento

\footnotetext{
${ }^{4}$ Cfr., OTERO LASTRES, J.M. "Reflexiones sobre el principio de 'unidad' en la nueva Ley concursal". En AA.VV. Aspectos de la nueva Ley Concursal -concursos, créditos, administradores, jueces-. Madrid: Editorial Reus, 2004. pp. 11 y ss.

${ }^{5}$ Véase, in extenso, CANDELARIOMACÍAS, M ${ }^{\mathrm{a}}$. I., Gestión de riesgos: impacto de la Ley Concursalen la compañía aseguradora y el seguro de crédito. Madrid: La Ley/Wolters Kluwer, 2009.pp. 13 y ss.

${ }^{6}$ Cfr., TORVISCO MANCHÓN, Beatriz. La información financiera en los procesos concursales. Barcelona: Bosch editor, 2005. p.11.

${ }^{7}$ Observemos las estadísticas que nos proporciona el Instituto Nacional de Estadística en cuanto al número de empresas que acuden a procedimientos concursales en ligazón con aquellas otras que estaban en un momento-período determinado, que sin embargo, desaparecen sin acudir a dichos procedimientos judiciales por haber utilizado otros mecanismos de resolución de tenor extrajudicial, al respecto, videhttp://www.ine.es
} 
general -concurso- suelen agregarse otra serie de procedimientos especiales, que responden a necesidades concretas por la urgencia o la tesitura del contexto económico en que se localizan, por la dimensión y su grave repercusión en el tejido económico, así como por sus particularidades tal y como sucede con las crisis de las entidades financieras. Asílas cosas -y según los sistemas jurídicos- se han desgranado diferentes acciones y procedimientos con fuerte intervención del Estado -como denominador común- en orden a solucionar las potenciales consecuencias negativas.

\section{II.1.- Antecedente directo (pero con matices) de la Ley Concursal española respecto al Reglamento (CE) 1346/2000, sobre procedimiento de insolvencia comunitaria.}

Para poder comprender de manera acabada los antecedentes más inmediatos de la Ley concursal española, podemos hallarlos, entre otros, en el Reglamento (CE) n ${ }^{\circ} .1346 / 2000$ (Diario Oficial de las Comunidades Europeas, n. ${ }^{\circ} \mathrm{L}$, de 30 de Junio de 2000) ${ }^{8}$, que obligaba a la modernización y racionalización del Derecho concursal español, que se calificaba por su carácter vetusto, dispersión normativa e inadecuación a la realidad circundante. De esta forma, la LCon española viene a adoptar y observar dicha reglamentación. Sin embargo, hay un extremo -en punto a la temática que estamos abordando- digno de remarcar como es el dato que si bien la Ley Concursal española no hace distinción en su presupuesto subjetivo, aunque admite ciertas especialidades ya aludidas y algunas más que se mencionarán en el siguiente epígrafe (II.2), por el contrario el Reglamento $\mathrm{CE}$, queda al margen de su ámbito de aplicación subjetivo a determinados sujetos, que por razones especificas (regulación especial) y por su singularidad, huyen del sistema general. Estos sujetos se encuadran dentro de las entidades financieras. Quizá una lectura meditada de este texto legislativo nos puede inducir a pensar que el legislador comunitario entendía las dificultades, que podría arrastrar la crisis de una de estas entidades, y que habría que adoptar otra serie de medidas o instrumentos que no tienen cabida en el abrigo de lo concursal. En efecto, no existe una mención expresa sobre quiénes quedan sometidos a esta regulación. Esta ausencia de referencias específicas hace que deba entenderse aplicable a todo tipo de personas susceptibles de ser afectadas por un procedimiento de insolvencia, con independencia de que sea persona física o jurídica, empresario mercantil o no, como se reconoce en el Considerando?.

\footnotetext{
${ }^{8}$ Vid.CANDELARIo MaCíAs, M${ }^{\mathrm{a}}$. I., "Aproximación a la iniciativa de Reglamento del Consejo Europeo sobre procedimientos de insolvencia (1999/C 221/06): Más de lo mismo?", Rivista di Diritto Falimentare (noviembre/diciembre 1999), n. ${ }^{\circ} 6$, pp. 1226-1260; idem, "Un examen sobre el Reglamento 1346/2000, del Consejo de Europa de 29 de mayo, sobre procedimientos de insolvencia comunitaria", Rivista di Diritto Falimentare (enero/febrero 2002), n. ${ }^{01}$, pp. 32-62; ibidem, "El Derecho Mercantil Internacional: La insolvencia con elementos extranjeros", CALVo-CARAVACA, A. L. / A REAL LudeÑA, S. (dir.), Cuestiones Actuales de Derecho Mercantil Internacional, Madrid: Colex, 2005, pp. 275-315.

${ }^{9}$ Expone el recorrido llevado a cabo por la vigente Ley concursal: PULGAR EZQUERRA, J."El acreedor hipotecario en la nueva legislación concursal". $\mathrm{N}^{\circ} .250$. Revista de Derecho Mercantil, 2003.pp.1425 a 1427: "reforma del Derecho concursal español...constituye una de las más importantes
} 
En cualquier caso, si en el articulado no hay una delimitación positiva sobre a quiénes afecta los procedimientos de insolvencia del Reglamento. Pero si hay una delimitación negativa en el art. 1.2: "El presente Reglamento no se aplicará a los procedimientos de insolvencia relativos a las empresas de seguros y a las entidades de crédito, ni a las empresas de inversión que presten servicios que impliquen la posesión de fondos o de valores negociables de terceros, ni a los organismos de inversión colectiva".

En este aspecto, adviértase de la existencia de una serie de normativa comunitaria ilustrada en la Directiva 2001/24/CE del Parlamento Europeo y el Consejo relativa al saneamiento y a la liquidación de las entidades de crédito. Asimismo, la Directiva 2001/17/CE del Parlamento Europeo y del Consejo relativa al saneamiento y a la liquidación de las compañías de seguros. Y otras referidas a la insolvencia del empleador en relación con sus trabajadores...

Luego, como anticipábamos, también el Considerando $n^{\circ} .9$, menciona esta excepción que justifica este hecho al tratarse de entes supeditados a regímenes especiales y sobre las que las autoridades nacionales disponen de amplias facultades de intervención.

En resumen: en lo que hace al presupuesto subjetivo decretado en el Reglamento (CE) va a ser de aplicación a cualquier persona sea física o jurídica, con naturaleza mercantil o no. No existe, por tanto, distinción alguna (concebido en sentido amplio), salvo las excepciones expresamente reconocidas por las normas ilustradas en las entidades financieras, ordenación que, precisamente, constituirá normativa paraconcursal como observaremos infra.

reformas acometidas en los últimos 50 años en España, a través de la Ley Concursal 22/2003, de 9 de julio, que se acompaña de la Ley Orgánica para la Reforma Concursal 8/2003, de 9 de julio, por la que se modifica la Ley Orgánica 6/1985, de 1 de julio, del Poder Judicial. Se aborda, por tanto, la modernización de nuestro obsoleto Derecho concursal sobre la base de un doble rango normativo, dado que la reforma incide no sólo en el ámbito de derechos fundamentales del concursado sino que, además, introduce importantes modificaciones en la Ley Orgánica del Poder Judicial con la creación de los nuevos Juzgados de lo Mercantil, habiéndose abandonado, no obstante, en el texto definitivamente aprobado la inicial incidencia de la reforma en el ámbito penal...la aprobación de la reforma española con una tendencia general reformista en el ámbito europeo y norteamericano, en el que diversos países se plantean la reforma de sus respectivos Derechos concursales (reforma italiana, francesa y portuguesa)... hay que valorar positivamente que, tras diversos intentos frustrados de reforma de nuestro Derecho concursal, que se remontan al ya lejano Anteproyecto de Ley Concursal de 1959 del Instituto de Estudios Políticos, al que seguirían la redacción de diversos borradores de Anteproyectos en 1976 por la Sección de Derecho Mercantil de la Comisión General de Codificación, presidida por Garrigues y, más recientemente, el Anteproyecto de Ley Concursal (en adelante, ALC) de 1983 y la Propuesta de Reforma conclusa el 12 de diciembre de 1995 y publicada por la Secretaría General Técnica con fecha 15 de febrero de 1996, se haya abordado finalmente y, además, con un amplio margen de consenso parlamentario la reforma del Derecho concursal español". In totum sobre la nueva Ley, MONEREO PÉREZ, J.L. La conservación de la empresa en la Ley concursal. Valladolid: Lex Nova, 2006.pp. 193 y ss. 


\section{2.-Una válvula de escape: Unidad procedimental versusDisposición Adicional $2^{\mathrm{a}} \mathrm{LCon}$.}

La finalidad del procedimiento concursal reglamentado en la Ley 22/2003, de 9 de julio de lo concursal ${ }^{9}$, encuentra su fundamento en sus precedentes ${ }^{10}$ proyecto de leyes concursales españolas- presentados uno ya al Ministerio de Justicia en su primera versión en el 2001, y otro, al Parlamento en julio de 2002-, es la mejor tutela del crédito (satisfacción de los acreedores) a través de diversas vías: sea la liquidación o conservación de la empresa (mediante soluciones negociadas -convenio y un plan de viabilidad). Con esta nueva Ley Concursal se pretende flexibilizar el procedimiento, esto es, en un único ${ }^{11}$ procedimiento ofrecer diversos cauces según la situación económico-patrimonial del deudor. Dejándose a un lado, -si es posible-, los múltiples defectos de los que adolecía nuestro sistema anterior, uno de ellos, el de la dispersión legal y pluralidad de procedimientos. Nuestra vigente LCon se inserta en un marco protagonizado por el intento comunitario de "superar la realidad asistemática existente hasta la fecha consistente en una combinación de Directivas y del Derecho privado internacional" ${ }^{12}$, que acentúa la complejidad del marco jurídico en el que los agentes económicos despliegan su actividad, propiciando así una mayor convergencia entre los sistemas de los Estados miembros. En este ámbito, constituye un referente de obligada mención la Ley alemana de Insolvencia (Insolvenzordnung, InsO) que, aunque publicada el 5 de octubre de 1994, entró en vigor el 1 de enero de 1999 derogando el Derecho concursal vigente hasta entonces, norma que persiste en el principio de universalidad jurisprudencialmente consagrado y en la que, además, el legislador alemán reconoce en la mayoría de los supuestos los procedimientos concursales de otros países (ex art. 102 InsO).

Por su parte, en este proceso de aproximación de los sistemas concursales, de posterior aparición-, el Reglamento (CE) no 1346/2000 ${ }^{13}$ del Consejo, de 29 de

\footnotetext{
${ }^{10}$ Según el parecer de FONT GALÁN, J.I., MIRANDA SERRANO, L.M., PAGADOR LÓPEZ, J. Y VELA TORRES, R.J."Viabilidad antritrust de las soluciones concursales de conservación de la empresa". $\mathrm{N}^{\circ}$.252. Revista de Derecho Mercantil, 2004. pp.477 y 478, "la Ley concursal de 2003 ha acogido un modelo híbrido de concurso en el que se combinan materiales normativos provenientes tanto del Anteproyecto de Ley Concursal de 1983, inspirado en el concepto social o socializante del concurso, como de la Propuesta de Anteproyecto de Ley Concursal de 1995, más inclinada hacia la concepción liberal o de mercado del concurso...de un modelo de concurso en el que -dentro de un generoso marco de flexibilidad- el legislador promueve con decisión y esfuerzo el principio de conservación de la empresa concursada como elemento rector de política legislativa".

${ }^{11}$ OLIVENCIA RUÍZ, M. Laterminología jurídica de la reforma concursal. Madrid: Iustel, 2006.pp. 147 y ss., se refiere a los diferentes criterios concurrentes de la unidad de la LCon, explicando detalladamente cada uno de ellos.

${ }^{12} \mathrm{Cfr}$., la Exposición de Motivos del Informe de 6 de noviembre de 2001 sobre la aproximación del Derecho civil y mercantil de los Estados miembros, COM (2001) 398-C5-0471/2001-2001/2187 (COS). Comisión de Asuntos Jurídicos y Mercado Interior.

${ }^{13}$ DOCE L 160 de 30 de junio de 2000. Véase, además, CANDELARIO MACÍAS, Ma . I., “Los vínculos entre el Reglamento 1346/2000, sobre procedimientos de insolvencia comunitaria y la Ley 22/2003 de lo concursalespañola". Vol. I . Estudiossobrela Ley Concursal. Librohomenajea Manuel Olivencia.Madrid:MarcialPons, 2005. pp. 681 a 718.
} 
mayo de 2000, sobre procedimiento de insolvencia ${ }^{14}$ comunitaria, en vigor desde el 31 de mayo de 2002 -como adelantábamos-, asegura el recíproco reconocimiento de los procedimientos de insolvencia en la Unión Europea ${ }^{15}$, imponiendo una línea de coordinación ${ }^{16}$, que necesariamente deberá presidir la legislación concursal de los Estados miembros, lo que de manera inevitable propiciará una semejanza del Derecho concursal de los distintos integrantes de la Unión ${ }^{17}$.

En cualquier caso y de nuestro texto concursal hemos de tener en consideración,-con carácter previo a cualquier reflexión-, cuál es la finalidad perseguida por la disciplina concursal de la Ley $22 / 2003^{18}$, para que una vez establecida ésta -como sostén sobre el cuál gravita el sistema concursal- podamos derivar el análisis de otras piezas de la cadena, que conforma esta ordenación. Dicho esto: ¿cuál es la finalidad perseguida? Parece claro que el texto pretende que la finalidad sea la mejor tutela del crédito ${ }^{19}$ tal y como anticipábamos; finalidad que puede realizarse por diversas alternativas: la continuidad de la actividad empresarial; la liquidación del patrimonio empresarial; la prevención de la situación de dificultades económicas y, sobre todo, con el punto de mira en garantizar-como nola seguridad jurídica del tráfico económico, es decir, el cercenar o impedir que actúen en el mercado operadores que no puedan pagar sus deudas ${ }^{20}$.

La utilización de los diversos parámetros descritos para conseguir el fin último: la satisfacción de los acreedores se ilustran en la determinación legal de cuáles son las circunstancias que permiten la apertura del concurso, cómo se ha de desarrollar y cuál es la solución (con sus límites), que se adoptará para resolver la situación de insolvencia ${ }^{21}$. Ello se concreta también, en la mayor o menor intervención

${ }^{14}$ Publicado en el Diario Oficial de las Comunidades Europeas de 30 de junio de 2000.

${ }^{15} \mathrm{Cfr}$. considerando (22) y arts. 16 y 17 del Reglamento comunitario $1346 / 2000$. ${ }^{16} \mathrm{Ex}$ considerando (3).

${ }^{17} \mathrm{Cfr}$. considerandos (21) y (31).

${ }^{18}$ Más información en genérico sobre la LCon, entre otras, la obra comentada de JIMÉNEZ SAVURIDO, Cristina. La nueva regulación concursal. Madrid: Colex, 2004. HERRERA CUEVAS, Edorta. Manual dela reforma concursal. Madrid: Europea de Derecho, editorial Jurídica, 2004.pp.59 y ss. SAGRERA TIZÓN, J.Ma Comentariosala Ley Concursal-Barcelona:Bosch,2004.CORDONMORENO, F.ComentariosalaLeyconcursal.Pamplona: Aranzadi, 2004. PULGAREZQUERRA, J. Comentariosa la legislación concursal: (Ley 22/2003y 8/2003parala reforma concursal). Madrid: Dykinson, 2004. AA.VV. (Dirs. QUINTANA CARLO, I., BONET NAVARRO, A. GARCÍACRUCES GONZÁLEZ, J.A.). Las claves de la Ley concursal. Pamplona: Thomson-Aranzadi, 2005. OLIVENCIA RUİZ, M. Lanueva Ley concursal. Madrid: CGPJ, 2005.

${ }^{19}$ Asíse pronuncia CANDELARIOMACÍAS, I. El convenio de continuación comomedio de protección del créditoen los procedimientos concursales. Granada: Comares, 1999. pp. 20-21. También en PULGAR EZQUERRA, J."El proyecto de Ley concursal de 2002: una aproximación crítica". N.550. Actualidad Jurídica Aranzadi, 24 de octubre de 2002.pp.1 a 8.

${ }^{20}$ Véase a VAN HEMMEN ALMAZOR, E. "La economía de la reforma y los costes del sistema concursal". $\mathrm{N}^{\circ} .4$. Revista Jurídica de Catalunya, 2003.pp. 47 y ss.

${ }^{21}$ Cfr., BELTRÁN, E."El problema del coste del concurso de acreedores: coste de tiempo y coste económico". En ROJO, A. (Director). La Reforma de la legislación concursal. Madrid: Marcial Pons, 2003.pp.323 y ss. 
judicial en el proceso y en la posible participación de los acreedores ${ }^{22}$, entre otros extremos.

Una vez establecida la finalidad, veremos ahora desde una perspectiva procesal como se ha distribuido la nueva Ley concursal, donde se ha tratado de reconducir la multiplicidad de procedimientos contenciosos internos del concurso -o de la vieja quiebra, o de la suspensión de pagos- a tres sistemas: al ordinario, al verbal o plenario rápido y al denominado 'incidente concursal'; este último presenta un carácter "especial a través del cual se ventilarán todas las cuestiones que se susciten durante el concurso y que no tengan señalada en la Ley otra tramitación distinta", cfr., la Exposición de Motivos de la Ley concursal; este llamado 'incidente concursal' se perfila procedimentalmente como una mezcla del ordinario y del verbal de acuerdo con la Ley No. 1/2000, de 7 de enero, de Enjuiciamiento Civil (LEC) ${ }^{23}$.

Antes de adentrarnos en el objeto de nuestro estudio resulta conveniente apuntar que el procedimiento concursal en su tramitación se halla supeditada a las diversas secciones en que éste se encuentra dividido, regulado por el artículo 183 de la LCon.

No olvidemos el planteamiento con que iniciábamos este estudio, en cuanto que la LCon consagra un único procedimiento denominado "concurso" 24 , informado por los principios de unidad legal, de disciplina y de sistema.

Aunque a decir verdad, la Exposición de Motivos de la LCon matiza que "la Ley ha respetado la legislación específica aplicable a las entidades de crédito, a las aseguradoras y a las operaciones relativas a los sistemas de pago y de compensación de valores o instrumentos financieros derivados, en gran parte impuesta por el Derecho de la Unión Europea, y que afecta a determinados aspectos del concurso. Sólo en defecto de normas especiales y en la medida en que sean compatibles con la naturaleza de aquellos sistemas, se aplicarán en esta materia las de esta Ley".

En lo que hace a las especialidades de la crisis de las entidades financieras, vienen contempladas no sólo por la Ley concursal, sino también por leyes especiales ${ }^{25}$ de manera dispersa y fragmentaria. Al propósito de reconducir el carácter dispar de la legislación que ha ido apareciendo en poco espacio de tiempo y en adecuación a la LCon, expresa LÓPEZ-BARAJAS PEREA ${ }^{26:}$ : "partiendo de esta falta de sistemática,

\footnotetext{
${ }^{22}$ Así se expresan CERDA ALBERO, F. y SANCHO GARGALLO,I. ¿Quiebra y suspensión de pagos. Claves para la reforma concursal", en publicaciones del Servicio de Estudios de la Caixa, en http:/ /www.estudios.lacaixa.comunicacions.com/webes/estudis.nsf/wurl/pbei025C0S_esp

${ }^{23} B O E \mathrm{~N}^{\circ} .7$, de 8 de enero de 2000. Cfr., al respecto, FAIREN GUILLÉN, Víctor. "La solicitud de concurso por el deudor en la nueva Ley concursal". №.251. Revista de Derecho Mercantil, 2004. p.226.

${ }^{24}$ OLIVENCIA RUÍZ, M. Laterminología jurídica de la reforma concursal. Madrid: Iustel, 2006, analiza en detalle los significados de dicho término en pp. 187 y ss.

${ }^{25}$ Un ejemplo reciente en el tiempo lo constituye, entre otros, el Real Decreto Ley 5/2005, de 11 de marzo, de reformas urgentes para el impulso a la productividad y la mejora de la contratación pública, (BOE $\mathrm{N}^{\circ} .62$ de 14 de marzo de 2005), que modifica y remite a la Ley 22/2003 en diversos aspectos que serán anotados a lo largo del desarrollo de este trabajo.

${ }^{26}$ LÓPEZ-BARAJAS PEREA, Inmaculada. La ejecución general administrativa. Op.cit. pp.80y 81.
} 
puede intentarse ordenar las normas que regulan las crisis de los sujetos de los mercados financieros de la siguiente forma: a) un primer grupo estaría constituido por las especialidades al procedimiento concursal general, aplicables dentro de la tramitación del concurso judicial ordinario cuando afecta a una entidad financiera... b) el segundo grupo estaría compuesto por las especialidades ajenas al procedimiento concursal en sede judicial. Todas estas medidas tienen en común que no necesitan, como presupuesto de su aplicación, que se haya iniciado el proceso concursal en sede judicial...c) en tercer lugar, las especialidades que afectan al interés de los acreedores y al patrimonio del deudor (masa pasiva y activa), que se van a determinar con aplicación de normas especiales que tienden a proteger las operaciones financieras, incluso si la insolvencia afecta a una entidad no financiera (como por ejemplo la inmunidad frente a las acciones de reintegración de la masa de las operaciones liquidadas a través de un sistema de registro, compensación y liquidación de valores)".

En cualquier caso, hemos de reiterar el hecho que desde la Exposición de Motivos de la LCon se pretende respetar la legislación especial y específica aplicable a las entidades financieras, a tal fin, hemos de atender al tenor de la Disposición Adicional Segunda ${ }^{27}$ de la LCon, que ordena el régimen especial aplicable a entidades de crédito, empresas de servicios de inversión y entidades aseguradoras ${ }^{28}$. Prescribe dicha Disposición Adicional 2a: 1. En los concursos de entidades de crédito o entidades legalmente asimiladas ${ }^{29}$ a ellas, empresas de servicios de inversión y entidades aseguradoras, así como entidades miembros de mercados oficiales de valores y entidades participantes en los sistemas de compensación y liquidación de valores, se aplicarán las especialidades que para las situaciones concursales se hallen establecidas en su legislación específica, salvo las relativas a composición, nombramiento y funcionamiento de la administración concursal. 2. Se considera legislación especial ${ }^{30}$, a los efectos de

\footnotetext{
${ }^{27}$ Sobre el particular, MAYORGA TOLEDANO, Ma ${ }^{\mathrm{a}}$.C."Crisis e insolvencia de las entidades de crédito". T.V.EnEstudios sobre la Ley concursal. Libro Homenaje a Manuel Olivencia. Madrid: Marcial Pons, 2005. pp.5443y ss. También VALENZUELA GARACH, F." La Ley concursal española de 9 de julio de 2003 como guía legislativa para el tratamiento de la crisis de las entidades financieras". T. V. En Estudios sobre la Ley concursal. Libro Homenaje a Manuel Olivencia. Madrid: Marcial Pons, 2005.pp.5756 y ss ${ }^{28}$ Analiza la Directiva 2001/17/CE sobre el saneamiento y liquidación de las compañías de seguros en MARTÍN CASTRO, $\mathrm{M}^{\mathrm{a}}$.Paz.ElSaneamientoylaLiquidación de Entidades Aseguradorasenelconcursodeacreedores. No.4.EstudiasdeDerecho Concursal. Navarra: Thomson-Civitas, 2006.pp.91 y ss.

${ }^{29}$ Según VIVES RUIZ, Fernando. "Régimen especial aplicable al concurso de entidades de crédito". Op.cit. p.775, "la Disposición Adicional segunda comentada se refiere a las 'entidades legalmente asimiladas' a las entidades de crédito. Esta referencia responde probablemente al hecho de que la redacción del art. 1.2 del Real Decreto Legislativo 1298/1986, anterior a la modificación operada por

la Ley Financiera circunscribía la noción de entidades de crédito a las de ámbito operativo universal (por ejemplo, el ICO, los bancos, las cajas de ahorros y la CECA y las cooperativas de crédito)". Al respecto y más en general: TAPIA HERMIDA. Derecho bancario. Zaragoza: Producciones Editoriales, 2002.

${ }^{30}$ Nótese que esta expresión "legislación especial" se va ir modificando, o mejor dicho añadiendo diversas leyes con el paso del tiempo que vendrán a englobarse bajo esta expresión de 'especial' respecto a la general que es la Ley concursal. Baste como ejemplo y de conformidad con el Real Decreto Ley 5/2005, de 11 de marzo, de reformas urgentes para el impulso a la productividad y la
} 
la aplicación del apartado 1, la regulada en las siguientes normas:

a) Ley 2/1981, de 25 de marzo, de Regulación del Mercado Hipotecario (artículo 14 y artículo 15, modificado por la Ley 19/1992, de 7 de julio, sobre régimen de las sociedades y fondos de inversión inmobiliaria y sobre fondos de titulización hipotecaria), así como las normas reguladoras de otros valores o instrumentos a los que legalmente se atribuya el mismo régimen de solvencia que el aplicable a las cédulas hipotecarias.

b) Real Decreto-ley 3/1993, de 26 de febrero, sobre medidas urgentes en materias presupuestarias, tributarias, financieras y de empleo (artículo 16).

c) Ley 24/1988, de 28 de julio, del Mercado de Valores (en lo que respecta al régimen aplicable a los sistemas de compensación y liquidación en ella regulados, y a las entidades participantes en dichos sistemas y, en particular, los artículos 44 bis, 44 ter, 58 y 59$)$.

d) Ley 3/1994, de 14 de abril, de Adaptación de la Legislación Española en Materia de Entidades de Crédito a la Segunda Directiva de Coordinación Bancaria (disposición adicional quinta).

e) Ley 13/1994, de 1 junio, de Autonomía del Banco de España ${ }^{31}$ (por lo que respecta al régimen aplicable a las garantías constituidas a favor del Banco de España, del Banco Central Europeo o de otros bancos centrales nacionales de la Unión Europea, en el ejercicio de sus funciones).

mejora de la contratación pública, que en su Disposición adicional tercera, modifica la Ley 22/2003, en particular, el apartado 2 de la disposición adicional segunda de la Ley 22/2003, de 9 de julio, Concursal, que queda redactado del modo expresado en el texto. De igual modo, sobresale la Ley 6/2005 (BOE No.97 de 23 de abril de 2005), sobre saneamiento y liquidación de entidades de crédito, en su Disposición final tercera. Carácter de Ley especial, que viene a agregar esta norma con carácter especial a la Disposición Adicional $2^{a}$ de la LCon.Al respecto, cfr., DE CASTRO ARAGONÉS, Juan Manuel y FERNÁNDEZ SEIJO, José $\mathrm{M}^{\mathrm{a}}$. "Los créditos de entidades financieras en la Ley concursal: reformas, contrarreformas y chapuzas legislativas (a propósito del RDLey 5/2005 de 11 de marzo sobre reformas urgentes para el impulso a la productividad y para la mejora de la contratación pública)". N.3. Revista de Derecho Concursal y Paraconcursal, 2005. p. 26.

${ }^{31}$ Véase, el Real Decreto Ley 5/2005, de 11 de marzo, de reformas urgentes para el impulso a la productividad y la mejora de la contratación pública, en su Disposición adicional cuarta, establece el régimen jurídico aplicable a las garantías constituidas a favor del Banco de España, del Banco Central Europeo o de otros bancos centrales nacionales de la Unión Europea, en el ejercicio de sus funciones, modificándose la Ley 13/1994, de 1 de junio, de Autonomía del Banco de España.Cfr., más sobre esta temática, VIVES RUIZ, Fernando. "Régimen especial aplicable al concurso de entidades de crédito, empresas de servicios de inversión y entidades aseguradoras". En FERNÁNDEZ DE LA GANDARA, L. y SÁNCHEZ ÁLVAREZ, M.M. a (Coords.). Comentarios a la Ley Concursal. Madrid: Marcial Pons, 2004.pp.791 y 792, “... se entiende por garantía cualquier depósito, prenda, operación simultánea, compraventa con pacto de recompra, afección, derecho de retención o cualquier otro negocio jurídico que recaiga sobre cualquier activo realizable, incluido el dinero en efecto, y tenga por finalidad asegurar los derechos y obligaciones derivados de cualquier operación presente o futura, concluida con el Banco de España, el Banco Central Europeo u otro Banco Central de la Unión Europea“. El autor añade cual es el régimen jurídico aplicable a este tipo de garantías. Muestra de la especialidad de las garantías financieras respecto a lo previsto en la LCon, lo manifiesta LEÓN, 
f) Ley 1/1999, de 5 de enero, Reguladora de las Entidades de Capital-Riesgo y de sus Sociedades Gestoras (disposición adicional tercera).

g) Ley 41/1999, de 12 de noviembre, sobre sistemas de pagos y de liquidación de valores.

h) Texto Refundido de la Ley de Contratos de las Administraciones Públicas, aprobado por el Real Decreto Legislativo 2/2000, de 16 de junio (artículo 100, apartado 5).

i) Texto Refundido de la Ley de Ordenación y Supervisión de los Seguros Privados, aprobado por el Real Decreto Legislativo 6/2004, de 29 de octubre (artículos 26 a 37, 39 y 59), y el Texto Refundido del Estatuto Legal del Consorcio de Compensación de Seguros, aprobado por el Real Decreto Legislativo 7/2004, de 29 de octubre.

j) Real Decreto-ley 5/2005, de 11 de marzo ${ }^{32}$, de Reformas Urgentes para el Impulso a la Productividad y para la Mejora de la Contratación Pública (capítulo II

Frco. J. "El régimen de reintegración concursal de las garantías financieras". Nº.6. Anuario de Derecho Concursal, 2005.p.354, piensa que "la regulación de las garantías financieras no se integra en el régimen general de garantías del Código civil y su contenido se aparta de este régimen en aspectos fundamentales. También ofrece serias dudas el tratamiento normativo de las garantías financieras en caso de insolvencia. El Real Decreto Ley 5/2005 parece haber pretendido ajustar el régimen de reintegración de las garantías financieras (arts. 15.5 y 16.3) con el sistema introducido la Ley concursal (art. 71 LCon). El contenido de estos preceptos no se corresponde, sin embargo, con los objetivos de la Directiva comunitaria".

${ }^{32}$ Examinan esta norma y su relación con la Ley concursal: DE CASTRO ARAGONÉS, Juan Manuel y FERNÁNDEZ SEIJO, José Ma ${ }^{\mathrm{a}}$. "Los créditos de entidades financieras en la Ley concursal: reformas, contrarreformas y chapuzas legislativas". Op.cit.pp.25 a 37, "(...) la urgencia y el mecanismo legal empleado por el Gobierno para realizar esta reforma pone de manifiesto que la Ley Concursal no fue lo suficientemente clara como para permitir que la protección del sistema financiero pudiera realizarse en sede de las normas generales de la Ley Concursal. (...) demuestra que la reducida experiencia de aplicación de la nueva Ley Concursal ha generado inquietud en el sistema financiero lo que ha llevado a la introducción de una reforma de gran calado por medio de una técnica legislativa peculiar, al emplearse un Real Decreto Ley en el que junto con normas sobre Mercado de Valores, medioambiente, sector eléctrico y energético cuela bajo el epígrafe de reforma urgente de impulso de productividad y mejora de contratación pública una alteración de reglas fundamentales del proceso concursal". Y se enumeran estas importantes transformaciones en la Ley concursal, así "1. Se establece un régimen específico a favor de los créditos de carácter financiero que rompe el principio de la par condicio creditorum. 2. Se habilitan mecanismos de extinción anticipada de contratos y compensación atribuidos unilateralmente al acreedor al margen de la administración concursal y del propio juez del concurso, comprometiendo o, por lo menos, pudiendo comprometer los mecanismos legales previstos por la Ley Concursal para garantizar la continuidad de la actividad empresarial (...) 3. Se fija un mecanismo de compensación y ejecución absolutamente independiente del proceso concursal lo que rompe también con la voluntad de que el proceso concursal pueda ser un proceso verdaderamente universal en la ejecución. 4. Las matizaciones efectuadas respecto del régimen de privilegios especiales unido a la práctica financiera y bancaria lleva a pensar que las entidades financieras van a quedar -por norma general- al margen de los posibles convenios que garanticen la continuidad dado que los privilegios derivados del Real Decreto Ley le van a permitir una ejecución separada que, paradójicamente, es más intensa que la prevista para las ejecuciones hipotecarias de bienes afectos a la actividad empresarial (...) 5. El derecho a la ejecución separada de las garantías 
del título I). (j) La Ley 6/2005, de 22 de abril, sobre saneamiento y liquidación de las entidades de crédito].

k) Disposición adicional tercera del Real Decreto-ley 9/2009, de 26 de junio, sobre reestructuración bancaria y reforzamiento de los recursos propios de las entidades de crédito.

3. Las normas legales mencionadas en el apartado anterior se aplicarán con el alcance subjetivo y objetivo previsto en las mismas a las operaciones o contratos que en ellas se contemplan y, en particular, las referidas a las operaciones relativas a los sistemas de pagos y de liquidación y compensación de valores, operaciones dobles, operaciones con pacto de recompra o se trate de operaciones financieras relativas a instrumentos derivados ${ }^{33}$.

Llamar la atención del análisis y lectura de la controvertida Disposición Adicional $2^{\mathrm{a}}$ de la LCon, el que contemple una lista de normas que se considerarán legislación especial a efectos de la aplicación del apartado 1 de dicha disposición. Ahora bien, esta lista se conforma de un conjunto dispar y heterogéneo de leyes ${ }^{34}$,

${ }^{33}$ Explica en este punto: PIÑEL LÓPEZ, E. "Efectos del concurso sobre los acreedores, los créditos, los contratos y los actos perjudiciales para la masa". $\mathrm{N}^{\circ}$. 2. Revista de Derecho Concursal y Paraconcursal, 2005.pp.36 y 37, "las normas especiales del apartado 2 de la Disposición Adicional $2^{\mathrm{a}}$. de la LCon, sólo se aplican en los concursos de entidades financieras. Sin embargo, las disposiciones especiales que se salvan, los acuerdos de compensación contractual (netting), las ventas con pacto de recompra, las operaciones dobles, la cesión de créditos empresariales, etc., regulan operaciones en las que intervienen una entidad financiera y otra que no lo es y la normativa salvada fija un régimen objetivo concursal para esas operaciones, que tiene eficacia cualquiera que sea la parte que caiga en concurso; cabe decir que el ámbito de aplicación contemplado en esos casos es, sobre todo, el de los concursos de los clientes de las entidades financieras, ya que los concursos de estas entidades son poco frecuentes, precisamente debido a la supervisión a que se encuentran sometidas y normalmente afectan a entidades de pequeño tamaño, marginales...este ámbito subjetivo ocasionó una inmediata reacción de los sectores afectados, denunciando que, en muchos casos, ello suponía incluso el incumplimiento de Directivas comunitarias y originaba al mercado financiero español una difícil situación, lo que ha obligado a la citada primera modificación de la Ley concursal, contenida en la Disposición Adicional $3^{a}$ de la Ley de Medidas de Reforma Económica 36/2003 de 11 de noviembre...la redacción supone una clara contradicción con el apartado primero, en el que se dice que las disposiciones del apartado 2 se aplicarán a los concursos de entidades de crédito y luego en el apartado 3 se afirma que las citadas normas se aplicarán con el ámbito subjetivo previsto en las mismas para, a continuación, hacer una referencia a unas determinadas operaciones, no a todas las contempladas por las normas que se citan en el apartado 2 de la Disposición Adicional $2^{\text {a". }}$

${ }^{34}$ En línea con un pensamiento ya reiterado de complejidad y dificultad de interpretación de la Disposición Adicional 2a , cfr., ROMERO MATUTE, Blanca. El Concurso de acreedores y las cesiones de crédito. $\mathrm{N}^{\circ}$.3. Estudios de Derecho Concursal. Navarra: Thomson-Civitas, 2005, anota en p.105, “(...) en puridad, lo que establece la d.a $2^{\mathrm{a}}$ de la Ley Concursal no es más que -con más o menos acierto, pues mezcla de manera confusa normas de derecho público con normas de derecho privado- una serie de excepciones puntuales a su ámbito de aplicación con un alcance muy concreto, y no una diferenciación entre ley general y ley especial, tal y como puede predicarse de la misma Ley Concursal en relación con la regulación de los procedimientos paraconcursales previstos para las entidades aseguradoras o la entidades de crédito en sentido amplio (...)". 
muchas de las cuales no se refieren al concurso de las entidades referidas en el apartado 1 de la Disposición Adicional segunda; sino por el contrario, a los efectos de las situaciones de insolvencia sobre determinadas operaciones financieras, aunque la insolvencia no afecte a una entidad financiera. Baste como ejemplo, la referencia a la Disposición Adicional Tercera de la Ley 1/1999, sobre régimen de determinadas cesiones de crédito. De conformidad con esta regla, de aplicación a las cesiones de créditos que se efectúen al amparo de un contrato de cesión que cumpla determinadas condiciones (entre ellas que el cedente sea un empresario, los créditos cedidos provengan de su actividad empresarial y que el cesionario sea una entidad de crédito), establece determinadas normas que podríamos considerar concursales; pues son de aplicación en caso de concurso del cedente o del deudor cedido, pero ninguna de las cuales tiene como presupuesto el concurso de una entidad financiera ${ }^{35}$.

Es más, -y sin alejarnos de nuestros objetivos-, debemos manifestar otro problema interpretativo de la Disposición Adicional $2^{\text {a }}$ derivado de la correlación entre el primero y segundo párrafo, en cuanto que si la relación o lista de normas especiales contenidas en el segundo apartado de la Disposición referida presenta carácter exhaustivo y cerrado y, en consecuencia, si cualquier norma relativa al concurso de entidades financieras no contemplada en la precitada relación y que se opongan o contradigan la Ley concursal queda derogada como derivación de la aplicación de su Disposición Derogatoria única.

Una interpretación coherente de ambos apartados nos conduce a afirmar que la respuesta al planteamiento expuesto debe ser positiva ${ }^{36}$, en cuanto que la Ley concursal posee "vis atractiva" y vocación de reglamentar de forma completa y unitaria todos los procedimientos concursales, tal y como se infiere del tenor de la Exposición de Motivos, por cuanto que la LCon opta por los principios de unidad legal, de disciplina y de sistema, dejando al margen, sólo las salvedades dispuestas por la propia norma. Y, a su vez, por lo contenido en la propia Disposición Adicional Segunda.

En este mismo ámbito, hay que estar con las palabras de VIVES RUIZ ${ }^{37}$,

-art. 15.5 del Real Decreto Ley- supone una modificación de los arts. 55 y 56 de la Ley Concursal permitiendo un supuesto de ejecución separada que contradice claramente el contenido del art. 55. 1 de la Ley Concursal (...) ejecución separada que puede desplegar sus efectos al margen del proceso concursal generando una evidente inseguridad respecto de las ejecuciones separadas iniciadas con base a esas garantías o las compensaciones realizadas al amparo de las normas de blindaje del sistema financiero. 6 . Se cercena de modo muy importante el régimen de acciones de reintegración y rescisión establecido en el art. 71 (...) en relación con las compensaciones de entidades financieras, desplazando la carga de la prueba de fraudulencia a la administración concursal, que puede toparse con una prueba diabólica que determine la imposibilidad de cumplir con el principio de protección de las masas activa y pasiva (...)".

${ }^{35}$ Cfr., VIVES RUIZ, Fernando. "Régimen especial aplicable al concurso de entidades de crédito". Op.cit.p.781.

${ }^{36}$ Así se expresa: VIVES RUIZ, Fernando. "Régimen especial aplicable al concurso de entidades de crédito". Op.cit.p.782.

${ }^{37}$ VIVES RUIZ, Fernando. "Régimen especial aplicable al concurso de entidades de crédito". Op.cit.pp.782 y 783. 
"advertir que ello no implica que queden derogadas todas las normas aplicables a las situaciones de crisis de las entidades financieras que no estén contempladas en la relación del apartado 2 de la Disposición Adicional segunda de la Ley concursal, en primer lugar, porque la mayoría de dichas normas no regulan propiamente el concurso de entidades financieras, sino medidas especiales para el tratamiento de las crisis de estas entidades, que pueden desembocar, o no, en una situación concursal, y, en segundo lugar, porque, en todo caso, sólo quedarían afectadas aquellas normas concursales que opusieran o fueran incompatibles con lo dispuesto en la Ley concursal".

Continuando con el análisis de la Disposición Adicional 2a ${ }^{\mathrm{a}}$, cabe apuntar que la técnica legislativa utilizada por el legislador concursal para dar efectividad al principio de vigencia de las especialidades de determinados sujetos por su estatuto o por imposición de la normativa de Derecho comunitario $^{38}$, -deja que desear-, ya que ésta se lleva a cabo a través de una Disposición Adicional -2 $-^{\mathrm{a}}$, que intenta dejar al margen ${ }^{39}$ las leyes que contienen las especialidades referidas.

Ante este panorama, el propio legislador concursal se ha dado cuenta del error en la técnica utilizada, además del riesgo y consecuencias que podrían derivarse, y por ello, ha querido reconocer que dichas excepciones y privilegios quedan en todo caso a salvo del régimen genérico. No resulta extraño, pues, que la Disposición Adicional $3^{a}$. de la Ley $36 / 2003^{40}$, de 11 de noviembre, de Medidas de Reforma Económica, modificase la LCon antes de su entrada en vigor para agregar el tercer párrafo del que consta ahora la Disposición Adicional segunda, con una clara intención aclaratoria para todos los operadores.

Hemos de subrayar, otra vez más, que el legislador concursal pretende que pese a la atracción de aquel sistema, se mantengan vigentes las disposiciones

\footnotetext{
${ }^{38} \mathrm{Vid}$., TORRALBA, Elisa. "La Ley sobre saneamiento y liquidación de las entidades de crédito". №.6. Anuario de Derecho Concursal, 2005. pp. 365 a 385, espec. p. 385, al plantear "se observa una tendencia a copiar de manera irreflexiva disposiciones comunitarias sin tener en cuenta que, en ocasiones, los contextos en que se van a aplicar las normas no van a ser coincidentes -eso ocurre, por ejemplo, en no pocos preceptos de la Ley concursal-, o que las limitaciones competenciales del legislador comunitario no son iguales a las de los legisladores nacionales, por lo que éstos pueden extender su regulación también a otros tipos de relaciones -con terceros Estados- y que no hacerlo supone establecer regulaciones incompletas".

${ }^{39}$ Cfr., LÓPEZ-BARAJAS PEREA, Inmaculada. La ejecución general administrativa. Op.cit. pp.90 y 91, indica: "entre las posibles técnicas a utilizar para dejar a salvo un cuerpo normativo tan disperso y poco homogéneo, esta disposición ha optado por un sistema mixto: en primer lugar declara su intención, que es que sigan aplicándose dicha 'legislación específica' a los concursos de las entidades financieras; y después enumera las normas que considera 'legislación especial' a estos efectos. La consecuencia inmediata iba a ser la no aplicación de dichas especialidades y privilegios en los concursos en los que la entidad afectada no era la entidad financiera, sino otra de carácter no financiera, que habría contratado con aquélla".
}

${ }^{40} \mathrm{BOE} \mathrm{N}^{\circ} .271$, de 12 de noviembre de 2003. 
sectoriales promulgadas con anterioridad ${ }^{41}$ a la LCon, que afectan de manera sobresaliente a las entidades financieras. No obstante, hay que anticipar aquí -será objeto de análisis a lo largo del trabajo- la propia Disposición excepciona -en su primer punto- a las legislaciones especiales en lo que hace a la composición, nombramiento y funcionamiento de la Administración concursal, que se regirán por lo ordenado en la LCon.

A modo de ejemplo, la legislación especial que se circunscribe en tomo a las entidades aseguradoras y que sería consideradas así en consonancia con la Disposición Adicional 2a , se ilustran en los artículos 26 a 37, 39 y 59 del Texto Refundido de la Ley de Ordenación y Supervisión de los Seguros Privados, aprobado por el RD Legislativo 6/2004 $4^{42}$, de 29 de octubre, ya anotado.

Al hilo de lo expuesto, se deriva de la interpretación de la Disposición Adicional $2^{\mathrm{a}}$ con relación al conjunto de la LCon que las normas aplicables al concurso de las entidades financieras, se concretarían del siguiente modo, a saber:

$1^{\circ}$.- Las disposiciones de la LCon sobre composición, nombramiento y funcionamiento de la Administración concursal, estimándose, obviamente, las especialidades para las entidades financieras previstas en la propia LCon.

$2^{\circ}$.- Las particularidades decretadas en su legislación especial.

$3^{\circ}$.- En ausencia de normas específicas y en la medida en que sean compatibles con la naturaleza de las entidades financieras, las normas de la legislación concursal.

\section{3. - Muestras (Leyes) de difícil naturaleza entre lo concursal y lo paraconcursal.}

A nadie escapa que en un entorno de crisis económica y financiera los diferentes operadores, especialmente, los gubernamentales y legales asuman sus responsabilidades e intenten por todos los medios posibles resolver las consecuencias negativas que se desgranan de una situación económica deficitaria y que afectan a intereses tan básicos (por ejemplo, crédito y empleo) de cualquier economía. El planteamiento descrito es hasta cierto punto comprensible, otra cuestión diferente es cuáles sean las herramientas o medios/técnicas más idóneos para llevar a efecto

\footnotetext{
${ }^{41}$ Incluso, en opinión de VIVES RUIZ, Fernando. "Régimen especial aplicable al concurso de entidades de crédito". Op.cit.p.782, "lo que se ha pretendido es asegurar la vigencia de las disposiciones incluidas en la Disposición segunda, con posterioridad a la entrada en vigor de la Ley Concursal y como especialidades al régimen general regulado en la misma. Pese a la dicción de la Ley, el punto de conexión no sería el concurso de una entidad financiera, sino normas que afectasen, directa o indirectamente, a las entidades financieras o a los mercados financieros en general, aunque no en todos los casos el presupuesto sea el concurso de tales entidades. Esta interpretación finalista y congruente con el espíritu de la norma parece más acertada que una mera interpretación literal, que llevaría al absurdo de declarar, por un mero error técnico, la derogación de normas que se citan expresamente en el tan mencionado apartado 2, que precisamente pretendía mantener su vigencia". ${ }^{42} B O E \mathrm{~N}^{\circ}$. 267, de 5 de noviembre de 2004.
} 
el alejamiento o salida de la crisis económica. Ante esta tesitura, los gobiemos suelen echar manos de legislación de urgencia para incidir sobre el problema acuciante o más intenso -del momento- de la crisis económica.

Bajo este recorrido, el legislador español no está aislado-ni es un caso apartecon respecto a lo que se hace en otros sistemas jurídicos y de este modo se procede a una proliferación de reglas, -que en muchas de las ocasiones perjudican más que benefician-, por emplear técnicas legales inadecuadas o bien por incidir sobre normas vitales como es en nuestro caso -La Ley Concursal- que vienen a provocar incoherencias interpretativas, incongruencias e inconsistencias que redundan, en definitiva, en una mala praxis o en soluciones no del todo satisfactorias.

El arsenal normativo-como puede entenderse- en estos últimos tiempos, se ha ido incrementando y solapándose con la Ley general (concursal). Y muestra de lo anterior es el Real Decreto-ley 3/2009, de 27 de marzo, de medidas urgentes en materia tributaria, financiera y concursal ante la evolución de la situación económica ( $B O E$ $\mathrm{N}^{\circ} .78$, de 31 de marzo de 2009) ${ }^{43}$, ya aludida. De una lectura minuciosa de esta norma nos podría asaltar la duda de si estamos ante una normativa concursal o paraconcursal, toda vez que se adoptan mecanismos para prevenir la situación de insolvencia y se faculta a determinados organismos públicos como es el caso del Consorcio de Compensación de Seguros a que se convierta en un asegurador para garantizar el buen fin de los seguros de crédito ${ }^{44}$. Estos datos son reveladores de la importancia de este ramo del seguro y, a la par, otra muestra de dicha aseveración se

\footnotetext{
${ }^{43}$ Entre otros autores, puede verse a FERNÁNDEZ VILLARIO, Roberto. "Novedades introducidas por el Real Decreto-ley 3/2009, de 27 de marzo, en materia concursal". No.4. Aranzadi Social, 2009. CORDON MORENO, F. Comentarios a la Ley Concursal. Tomo I y II. Aranzadi, 2009. Y, en especial, el monográfico número 11 de la Revista de Derecho Concursal y Paraconcursal, 2009, que dedica varios artículos a examinar con exhaustividad las diferentes modificaciones habidas por esta norma. ${ }^{44} \mathrm{En}$ el tenor de la Ley se contemplan diversas medidas destinadas a paliar la situación de crisis. Comentar que una de las formulas previstas, que vienen a aliviar la situación de crisis económica y que se interrelación con el Derecho de la insolvencia es el seguro de crédito, que se estimula otorgando al Consorcio de Compensación de Seguros -instituto de naturaleza pública- una función reaseguradora en el funcionamiento de dicho ramo. En los tiempos actuales de crisis económica y financiera uno de los principales síntomas que se deriva de la enfermedad "crisis" es, cabalmente, la situación de insolvencia, como hito revelador del avance de aquella enfermedad. Ante esto, el Ordenamiento jurídico tiene que actuar y para ello hacemos uso de la "medicina" ilustrada en la regulación concursal, pero junto a ésta existen otros mecanismos paliativos que incidente directamente en la insolvencia y buen reflejo de ello es el contrato de seguro de crédito, que intenta eliminar o suavizar en la medida de lo posible las consecuencias derivadas de aquel hito. En efecto, no podemos pasar por alto la virtualidad del seguro de crédito, ramo del seguro no tratado con la debida amplitud que merece; reflejo de lo dicho son los datos macroeconómicos en torno a esta institución, baste decir que en el año 2008, cerca de 45.000 empresas españolas contaban con un seguro de crédito ylacartera deempresasclientescubiertassuperabalacifrade 1.3 millones, con unimportetotaldelasoperaciones decrédito aseguradas deunos 200.000 millonesdeeuros. Mientras, lasindemnizacionespagadasalosaseguradosrondaronlos 800 millones deeuros.SegúnlasúltimasestadísticasdeICEA, elvolumenestimadodeprimasdelsegurodecréditosesituóenaproximadamente 836millones deeuros. Seestimaquelacobertura delsegurodecréditosobreel total delasoperacionesa créditoesdel $30 \%$, porlo queEspañasesitúacomoelmercadoconmayorpenetración deesteseguroyelquintodelmundoportamaño.Sobrelosdatos, véase el Boletín Diario de Seguros (BDS) de 30/3/2009, editado por INESE, ISSN: 1697-4182
} 
ilustra en la reforma introducida por el Real Decreto-Ley 3/2009, de 27 de marzo, de medidas urgentes en materia tributaria, financiera y concursal ante la evolución de la situación económica. En el preámbulo de esta norma se declara "la habilitación al Consorcio de Compensación de Seguros para que pueda desarrollar actividades de reaseguro del crédito y la caución, ante las dificultades aparecidas en el mercado internacional de reaseguros, circunstancia que incide muy negativamente en las relaciones comerciales entre empresas". Dicha pretensión se concretiza en el Capítulo II, artículo 4. Al respecto, -y en líneas generales-, se viene a decretar que el Estado participará en las operaciones de seguro de crédito a través del Consorcio de Compensación de Seguros, que se convierte así en reasegurador, aunque se limitan los riesgos que asumen las aseguradoras y con ello "se garantiza que las empresas puedan seguir vendiendo a crédito a sus clientes". El Consorcio asumirá un riesgo de hasta 200 millones de euros, siendo uno de los beneficiarios directos las PYMES, al estar supeditadas a mayor presión para vender a crédito a sus clientes y hallarse con más trabas para acceder a otras fuentes de financiación. En cualquier caso, déjese claro que el Consorcio de Compensación de Seguros funcionará bajo los mismos condicionantes económicos que los operadores de reaseguro y, a su vez, ejecutará un control de los riesgos asociados al crédito que se conceden a las empresas, extremo que beneficia al mercado crediticio y la economía global.

Otra de las medidas dirigidas a mitigar los efectos de la crisis económica viene dada según este Real Decreto por "facilitar la refinanciación de las empresas que puedan atravesar dificultades financieras que no hagan ineludible una situación de insolvencia, además de, agilizar los trámites procesales, reducir los costes de la tramitación ....", según la Exposición de Motivos de la norma referida.

Pero hay más, junto a estas medidas de tenor netamente paraconcursal, se agregan otras medidas que afectan al cuerpo, la identidad y sentido de la Ley concursal al incidir sobre el convenio anticipado, el procedimiento abreviado, la publicidad del concurso, a las diferentes soluciones del concurso, entre otras, cuyo estudio desbordaría nuestro objeto de examen en esta contribución.

Dentro del rosario de disposiciones que podríamos traer a colación respecto a la difícil calificación de concursal o paraconcorsal, cabe mencionar otra regla significativa por el dato de que los procedimientos paraconcursales no sólo incidirían en las grandes empresas o en las entidades financieras ${ }^{45}$ por su impronta en la economía, sino que también actúan sobre las Pequeñas y Medianas Empresas (PYMEs), y muestra de ello es el Real Decreto-Ley 10/2008, de 12 de diciembre, por el que se adoptan medidas financieras para la mejora de la liquidez de las pequeñas y

${ }^{45} \mathrm{~A}$ modo de ejemplo, dentro del nuevo abanico reglamentario, véase el Real Decreto-ley 9/2009, de 26 de junio, sobre reestructuración bancaria y reforzamiento de los recursos propios de las entidades de crédito (BOE $\mathrm{N}^{\circ}$. 155, de 27 de junio de 2009), especialmente, en su Capítulo II y III. Véase, además las reflexiones de MELÉNDEZ HUELIN, O. "Derecho concursal y normativa contable del Banco de España: provisiones por insolvencia y alternativas al concurso de acreedores". №.10. Revista de Derecho Concursal y Paraconcursal, 2009.pp. 241 a 260. 
medianas empresas, y otras medidas económicas complementarias (BOE $\mathrm{N}^{\circ}$. 300, de 13, de diciembre de 2008) ${ }^{46}$. En este contexto, traigo a colación lo que se expresa en el preámbulo de la norma, al decir: "se ha venido deteriorando profundamente la situación de los mercados financieros internacionales, con el consiguiente impacto negativo sobre la actividad económica real y sobre la confianza de los agentes económicos. Una de las consecuencias más destacables de la crisis financiera es la disminución de la capacidad de las entidades financieras para captar recursos en los mercados de capitales. La incertidumbre sobre los riesgos de crédito y contrapartida ha distorsionado el buen funcionamiento de los mercados, dificultando la captación de recursos por parte de las entidades financieras y, en último término, la financiación a empresas y familias (...)Ante las circunstancias extraordinarias que se están produciendo en los mercados financieros, los Gobiernos europeos y, en particular, el Gobierno español han venido adoptando un conjunto de medidas excepcionales cuyo objetivo último es permitir que los flujos de crédito puedan llegar con normalidad a familias y empresas, de forma que las decisiones de consumo, ahorro e inversión puedan adoptarse en un entorno adecuado. (...)En este contexto, el Gobierno español ha considerado indispensable aprobar una nueva línea de mediación del Instituto de Crédito Oficial para atender las necesidades de financiación de capital circulante de aquellas pequeñas y medianas empresas que, siendo solventes y viables, estén sometidas a una situación de fuerte restricción de crédito".

Como puede deducirse del tenor literal de la Exposición de Motivos, la situación demanda de la intervención estatal para evitar que una cantidad importante de empresas acudan a procedimientos concursales, intervención que se refleja en ayudas estatales y otra serie de medidas legales bajo supervisión del Estado. De suerte que dichos mecanismos podríamos incluirlos dentro del paraguas protector de los procedimientos paraconcursales por plantear finalidades netamente preventivas ante el concurso.

\section{III.-La disciplina de los procedimientos paraconcursales.}

Hemos de comenzar este asunto ubicándonos en un momento histórico de la legislación española-que por otro lado resulta cíclico y ahora se muestra con especial virulencia- que tendrá también su influjo -de similar forma- en otros ordenamientos concursales y es el hecho del necesario acoplamiento entre las normas concursales y los procesos económicos reales, que se han llevado a cabo, en la práctica, tal y como señala el Prof. VERDERA ${ }^{47}$ mediante un "creciente arsenal de técnicas desde las

\footnotetext{
${ }^{46}$ Cfr., al respecto, ALCOVER GARAU, G. "El Real Decreto Ley 10/2008, de 12 de diciembre, por el que se adoptan medidas financieras para la mejora de la liquidez de las pequeñas y medianas empresas, y otras medidas económicas complementarias". №.10. Revista de Derecho Concursal y Paraconcursal, 2009.pp. 461 a 463.

${ }^{47} \mathrm{En}$ el tiempo hay que retrotraerse a las posturas doctrinales de VERDERA Y TUELLS, E."Aspectos económicos y jurídicos de la reforma del Derecho concursal: la supervivencia de las empresas en crisis".No.8. Revista de la Universidad Complutense. Madrid: Facultad de Derecho, 1985.p. 184. Defienden igual planteamiento, SÁNCHEZ DE MIGUEL, Mª.C."Crisis económica y Derecho concursal".
} 
moratorias clásicas a las técnicas de subvención pura y simple", alejándose del Derecho Concursal propiamente dicho para acudir a un Derecho paraconcursal ${ }^{48}$. En mi opinión, se comprende por normativa paraconcursal aquel conjunto de reglas que se han venido promulgando en atención a las necesidades concretas del caso que se presentaba y, en gran medida, como consecuencia de las crisis económicas de aquellos sectores más significativos de la economía de un país, fundamentalmente,

Madrid: Consejo General de colegios de economistas de España, 1984.p.114; vid., en este apartado, GARCÍA VILLAVERDE, R. "Notas sobre la Reforma del régimen jurídico de la crisis de las empresas bancarias". No N $^{\circ}$ 18. Papeles de Economía Española, 1984.p.136, "las instituciones paraconcursales han ido creciendo progresivamente, con apresuramiento, sin una visión global de los problemas que permitiera su sistematización adecuada y, en todo caso, como un instrumento importante de política económica y social"; VACAS MEDINA, L. "La Reforma de nuestro Derecho Concursal". N.465. Revista General de Derecho, junio, 1983. p.49. En este contexto, resulta importante el trabajo de ROJO, A. "Aspectos civiles y mercantiles de las crisis bancarias". $N^{\circ} .29$. Revista de Derecho Bancario y Bursátil, enero-marzo, 1988, donde realiza un estudio exhaustivo del Derecho paraconcursal aplicado a las crisis bancarias. En este sentido, en la p.114 explica que "se crean sucesivos instrumentos jurídicos para el tratamiento de la crisis bancaria", dando buena muestra de manera sistemática de lo acaecido sobre este particular. Añade, "se modifica la política de saneamiento en función de criterios heterogéneos (dimensión de la entidad en crisis, grado de endeudamiento del Fondo de Garantía de Depósitos en Establecimientos Bancarios frente al Banco de España, etc.). Concluye en la p.143, "al lado del Derecho concursal nace, por las exigencias de la realidad, un derecho paraconcursal bancario". También, ESPINA, A. "La crisis del Sistema concursal español". $\mathrm{N}^{\circ}$.727.Información Comercial Española, marzo, 1994.p.24 puntualiza que al no utilizarse el Derecho concursal, solo cabía apelar a quitas y esperas de los acreedores públicos, a ayudas y crédito oficiales, a condonaciones voluntarias de los acreedores, y al eventual sacrificio de los accionistas, cuando esto último resulta imposible. VICENT CHULIÁ, Frco.Introducción al Derecho Mercantil.9a .edic.Valencia: Tirant Lo Blanch, 1996.p.661. En el ámbito del Derecho comparado, en concreto, en el Derecho italiano, cfr., al maestro RAGUSA MAGGIORE, G. Scritti di Diritto commerciale e fallimentare. Vol. II. Cedam, 1997.pp. 769 a 775.

${ }^{48}$ Conforme apunta ROJO, A. "Aspectos civiles y mercantiles de las crisis bancarias".Op.cit.p.144, hemos de considerar que "el Derecho paraconcursal se caracteriza bien por la especialidad, en cuanto que se ha desarrollado en sectores económicos especiales, precisamente, aquéllos en los que el ordenamiento jurídico determina potestades de vigilancia y control, bien por la excepcionalidad, al aplicarse a impresas o grupos de empresas que por razones de dimensión o de complejidad hacían entrar en juego el criterio político de oportunidad. Aunque con frecuencia se presentan formalmente como soluciones preconcursales, las medidas administrativas y asimiladas de intervención y saneamiento de empresas en crisis constituyen en realidad, soluciones alternativas a las típicamente concursales. Por lo general, a través de ellas no se trata de evitar la crisis, sino sencillamente eliminarla o, en otro caso, paliar sus negativos efectos". Sea como fuere, también, se debe subrayar lo que ponía de manifiesto GARCÍA VILLAVERDE, R."Notas sobre la reforma del régimen jurídico de la crisis de las empresas". Op.cit.p.135, "el resultado ha sido una red enmarañada de disposiciones de diverso rango, unas veces de aplicación general, pero en la práctica hechas a la medida del caso concreto". Insiste en que "se trata de una respuesta a las necesidades derivadas de las transformaciones del sistema, porque la función primordial es ir remediando los problemas que plantea la progresiva inadaptación del viejo Derecho Concursal para atender adecuadamente a los nuevos hechos". Más cercano en el tiempo, in totum, LÓPEZ-BARAJAS PEREA, Inmaculada. La ejecución general administrativa de las entidades aseguradoras. Madrid: Colex, 2004.p.29. In totum, ÁLVAREZ VEGA, M". I. "Soluciones concursales y paraconcursales a la crisis de empresa. La función conservativa del concurso de acreedores en la Ley 22/2003, de 9 de julio, concursal". No s. 9-10. Revista de Derecho Privado, septiembre, 2004. 
las entidades financieras, integradas por las entidades de crédito, seguros y agentes de inversión. Con estas reglamentaciones se introducía un tratamiento y soluciones a los problemas jurídicos modemos a distinto nivel que el ofrecido por el marco general concretado en los procedimientos concursales, que quedaban de esta manera al margen.

En resumen, al no existir un ajuste con la legislación concursal común o general, se ha fijado una normativa dependiente de la situación coyuntural lo que ha conducido al legislador a dotar de una solución puntual y concreta para el caso que lo requería y que, por diversos motivos, se sustraía de la norma general, provocando -en gran número de ocasiones- inseguridad jurídica para los operadores.

A nadie le pasa por alto que las empresas del sector financiero entre las que se encuentran las entidades de crédito, compañías aseguradoras y entidades de servicios de inversión, están sujetas a una estrecha vigilancia y supervisión por parte de la Administración y a fuerte potestades administrativas de ordenación, toda vez que se tiene la mirada puesta en la tutela de los intereses generales representados tanto por la propia seguridad del sistema financiero como por los derechos e intereses de los asegurados, inversores, depositantes, ahorradores y, en general, de los clientes de estas empresas. En definitiva, es la confianza y la seguridad jurídica del sistema crediticio y financiero lo que se evalúa y considera.

$\mathrm{Y}$ en consonancia con tales intereses generales no es de extrañar que el Ordenamiento jurídico posibilite medidas variadas para tutelarlos en los supuestos de crisis empresarial, entre otras, ha venido usándose la intervención de la empresa, la liquidación intervenida o la liquidación administrativa forzosa, pero no, exclusivamente, para atender supuestos de crisis empresariales ${ }^{49}$, sino en adecuación a otros supuestos diferentes, que se encuadran dentro del término genérico -ya referido- Derecho paraconcursal, y que, por ende, se hallan al margen del Derecho concursal por ordenarse fuera de esta norma en otras de carácter especial y específico.

Observamos así que pese a la pretendida unidad, -que quería nuestro legislador concursal y ya anotadas algunas reglas específicas y especiales-, el Ordenamiento Jurídico permite que algunas entidades financieras, entre ellas la Banca y las Compañías Aseguradoras, en situación de insolvencia o crisis empresarial queden exentas del concurso de acreedores mediante las técnicas de saneamiento ${ }^{50}$

\footnotetext{
${ }^{49}$ PRIEGO PÉREZ, J."Tratamiento Jurídico de las crisis bancarias". En Lecciones de Derecho Bancario y Bursátil,2001.pp.95y ys. DEL GUAYO CASTELLLA, Iñigo. Sector públicoempresarialeinstitucionesparaconcursales. Madrid: Marcial Pons, 2004. p.227.

${ }^{50}$ LÓPEZ-BARAJAS PEREA, I. y GÓMEZ-SANCHA TRUEBA, I."Especialidades del concurso de las entidades financieras tras la nueva Ley Concursal". $\mathrm{N}^{\circ}$.254. Revista de Derecho Mercantil, 2004.p.1544, "la confianza en los intermediarios financieros a los que se encomiendan los ahorros o inversiones juega un papel fundamental en el conjunto del sistema. De hecho, las situaciones de crisis que les afectan pueden producir un riesgo de contagio al resto de intermediarios por la disminución de confianza y consiguiente retraimiento de los inversores y ahorradores. En efecto, el objetivo esencial que persigue toda la llamada regulación prudencial no es otro que evitar la aparición de crisis entre aquellas entidades que conforman el tejido del sistema". Además, véase, LAGO GIL, R. "La tutela de los depositantes ante las crisis financieras de las entidades de crédito. En particular, el supuesto de las cuentas con varios titulares". No.58. RDBB, abril-junio, 1995.pp.393 y ss.
} 
u otras de corte administrativo. Nos encontramos, pues, que junto a las técnicas propiamente paraconcursales, y dentro del Derecho aplicable a las entidades del sector financiero se agregan medidas e instrumentos tendentes a la satisfacción del crédito de los depositantes e inversores, en tal sentido tienen particular relevancia el Fondo de Garantía de Depósitos ${ }^{51}$, el Consorcio de Compensación de Seguros y el Fondo de Garantía de Inversiones, instituciones creadas, precisamente, para tratar de garantizar la devolución de las imposiciones e inversiones.

Puntualicemos otra vez que en la legislación concursal española general (2003) ahora vigente no se contemplan -expresamente y como no podría ser de otro modo- procedimientos paraconcursales en base a que lo buscado por esta Ley insistimos- es la centralización y concentración en el texto referenciado de todos los supuestos de insolvencia y su reglamentación. Quedando derogada la normativa anterior sobre Administración Judicial de empresas embargadas; la normativa sobre reconversión industrial y todas aquellas legislaciones específicas y complementarias que conformaban un arsenal importante de legislación paraconcursal nacida de las circunstancias concretas de dificultades o crisis económica. Ahora bien, esto no significa -como anticipábamos- que no se tengan en cuenta las especialidades inherentes a la insolvencia de determinados sujetos.

Unido a todo lo anterior, subráyese que la especialidad del sujeto deudor no es inconveniente para que le sea de aplicación la Ley general (2003). En tal sentido, véase el presupuesto subjetivo contemplado en el art.1 de la Ley, donde sólo se excluyen sólo a los organismos públicos y territoriales de su ámbito de aplicación.

Otra posible especialidad la podríamos hallar en aquellos sujetos que por su entidad (pasivo no superior a 10.000 .000 de euros) ${ }^{52}$, le es aplicable un procedimiento abreviado (2003/2009, ex arts. 190 y 191), si bien esta excepción no puede considerarse como un procedimiento paraconcursal, ya que aparece reglamentada dentro del procedimiento general.

No obstante lo dicho, hemos podido constatar como en tiempos de crisis económica las pretensiones ab inito del legislador y, según la necesidad "acuciante" del momento, se ha promulgado un rosario de reglas que "a salto de mata" han entorpecido la buena marcha o el camino recto de la legislación concursal.

Sea como fuere, corresponde -a continuación- saber si estas consideraciones de carácter general para el Derecho español se trasladan al resto de legislaciones concursales, esto es, si existe un hilo conductor sobre esta cuestión.

${ }^{51}$ Cfr., para más información, el Real Decreto Ley $\mathrm{N}^{\circ} 18 / 1982$, de 24 de septiembre, que regula el Fondo de Garantía de Depósitos, y el Real Decreto Ley No.2620/1996, de 20 de diciembre; Orden ECO/316/2002, de 14 de febrero, por la que se establecen las aportaciones al Fondo de Garantía de Depósitos en Cooperativas de Crédito. Más información en FRANCH I SAGUER, M.Intervención administrativa sobre bancos y Cajas de Ahorro. Madrid: Civitas, 1992.pp. 353 a 373. GARCÍA DE ENTERRÍA, J."La reforma del régimen del Fondo de Garantía en Establecimientos Bancarios". No.55. Revista de Derecho Bancario y Bursátil, 1994.pp.569 a 594.

${ }^{52}$ Modificado por el Real Decreto Ley 3/2009, con anterioridad -versión original 2003- la cantidad era de 1 millón de Euros. 


\section{1.- Perspectiva comparada de los procedimientos paraconcursales.}

Se atisba dentro del marco del Derecho concursal europeo ${ }^{53}$, en particular, en el Derecho alemán, InsO (1999), una disciplina sobre la situación de la insolvencia, que abarca a múltiples sujetos que caben dentro del régimen general, si bien exceptuando las propias salvedades que expresamente así se contemplan dentro de la Ley general- InsO-. Véase, en tal sentido, el artículo 11 de la InsO, que afecta desde sociedades sin personalidad jurídica hasta la herencia, y a toda persona jurídica o natural. Y esto es así por la tendencia a centralizar la normativa en una legislación común, ahora bien, también se excluye de manera explícita a las personas jurídicas de Derecho Público. Establece el artículo 12: "I. Es inadmisible el procedimiento de insolvencia sobre el patrimonio: 1. Del Estado Federal o de un Estado (Land); 2. De una persona jurídica de Derecho Público sujeta a la vigilancia de un Estado, si así lo determina el derecho del Estado. II. Si de conformidad con el punto I, número 2, el Estado tiene declarado inadmisible el procedimiento de insolvencia sobre el patrimonio de una persona jurídica, pueden los trabajadores, en caso de insolvencia o de sobreendeudamiento de esa persona jurídica, reclamar del Estado (Land) las prestaciones que a ellos les correspondería, para el supuesto de apertura del procedimiento de insolvencia, de la Oficina de trabajo, de conformidad con las disposiciones de la Ordenanza de fomento del trabajo relativas a la falta de dinero en la insolvencia, y del Organismo de previsión de la insolvencia, de conformidad con las disposiciones de la Ley para la reforma del servicio de previsión de jubilación".

Ítem más, en el Título X, de la InsO alemana (1999) se reconoce las clases especiales de procedimientos de insolvencia: el procedimiento de insolvencia de la herencia; procedimiento de insolvencia sobre el patrimonio de una comunidad conyugal continuada y procedimiento de insolvencia sobre el patrimonio de una comunidad conyugal administrado conjuntamente. Aunque estos procedimientos se encuadran dentro de especialidades dentro del régimen general, pero en ningún caso se podrán considerar como procedimientos paraconcursales.

Al fin y al cabo, si resulta claro que la Administración pública queda excluida del ámbito de aplicación de la InsO, en los supuestos de crisis o dificultades económicas de estos entes tal y como se describen en el artículo 12, donde se le aplicarán otra legislación especial y conexa a la InsO, que vendría a conformar un arsenal de índole administrativo, que configuraría aquí sí el Derecho paraconcursal de este país.

En la misma línea de actuación que el Derecho español y alemán, nos encontramos con el Real Decreto núm. 53/2004 portugués, toda vez que en su ámbito de aplicación se excluyen a determinados sujetos $\mathrm{y}$, por ende, a estos supuestos le serán aplicables otras reglas fuera del

\footnotetext{
${ }^{53}$ Para más información, cfr., los casos examinados por GUAYO CASTIELLA, I., "Paraconcursalidad preventiva y entidades financieras: nacionalizaciones bancarias en Europa (Northern Rock) y Estados Unidos (INDYMAC)". Nº.9. Revista de Derecho Concursal y Paraconcursal, 2008. pp. 457 a 463.
} 
régimen general conformando los denominados procedimientos paraconcursales, que son objeto de nuestra atención.

En efecto, en esta legislación se exceptúan las personas colectivas públicas, las entidades públicas empresariales y las empresas de seguros, las instituciones de crédito, las sociedades financieras, las empresas de inversión, que presten servicios que conlleven la posesión de fondos o de valores mobiliarios de terceros y los organismos de inversión colectivo, en la medida en que la sujeción al proceso de insolvencia sea incompatible con los regímenes especiales previstos para tales entidades. No obstante lo anterior, se limita la no aplicación de las reglas del Código sólo a aquellos supuesto en que estas normas sean incompatibles con los regímenes especiales aplicables a estas entidades, con lo cual, cuando no se produzca esta circunstancia, quedarán sometidas al ámbito de aplicación del Código. Si observamos detenidamente sigue la línea de argumentación que las anteriores normativas y, en consonancia, -como anotábamos- con los imperativos del Reglamento ${ }^{54}$ (CE) 1346/2000, sobre procedimientos de insolvencia comunitaria.

Además de lo reseñado, subráyese que dentro del régimen general se contemplan supuestos especiales, aunque no hay que considerarlos como procedimientos paraconcursales al integrarse dentro de la legislación general, así se disciplinan Reglas específicas de sociedades comerciales y, a su vez, Disposiciones específicas de la insolvencia de personas naturales, entre estas, el fiduciario y, por último, la normación de la insolvencia de los no empresarios y titulares de pequeñas empresas.

Así las cosas, si echamos la mirada atrás en el tiempo, podemos vislumbrar cómo la legislación portuguesa y en función de las circunstancias y crisis coyunturales se han creado normas de índole paraconcursal al margen del procedimiento común ilustrado en el Código de la insolvencia (2003) con el fin de reestructurar, salvar o liquidar, según los casos, de manera ordenada los activos de empresas de cierta envergadura o por intereses de tenor político.

Por el contrario a lo que sucede en las legislaciones alemana y española, en Francia trámite su aún vigente Ley n84-148, 1984, relativa a la prevención y al acuerdo amigable de las dificultades de las empresas, se prescribía una reglamentación diversa para determinados entes que se escapan del régimen general. De este modo el art. 59 decreta de manera clara que "un Décret en Conseil D'Etat adaptera, pour les banques et les entreprises de réassurance, les dispositions des articles 340-1, 341-2 de la Loi du 24 juillet 1966 précitée, en particulier la forme et le contenue des documents qui doivent être établis. L'application de la présente loi aux entreprises d'assurance et de capitalisation s'effectue dans les condictions prévues par l'article L.310-3 du Code des assurances". Luego, los bancos y las

\footnotetext{
${ }^{54}$ Véase el Reglamento 1346/2000 sobre procedimientos de insolvencia comunitaria, también excluye de su ámbito subjetivo de aplicación a estos sujetos por hallarse supeditados a una reglamentación específica derivado de los múltiples intereses que acarrea una situación de crisis o dificultades económicas en estos entes tal y como explicábamos ut supra.
} 
empresas de seguros poseen su legislación especial.

Subráyese que en la legislación francesa los entes públicos entrarían dentro del ámbito de aplicación de esta Ley francesa, según se prescribe en el art.30 destinado a determinar la información financiera y control de cuentas dentro de ciertas empresas públicas. Pero, insistimos, las entidades de seguros, así como la Banca en el supuesto de dificultades económicas habrán de acudir, sin embargo, a otra legislación que no es la aplicable por la Ley de prevención de dificultades del año 1984.

Por su lado, -y más reciente en el tiempo- el Código de Comercio frances (2000) a través de su Libro IV, establece un régimen general, si bien con particularidades de índole administrativa al final de su reglamentación al disponer disposiciones especiales aplicables a los Departamentos de Haut-Rhin, Bas-Rhin y Moselle, excepcionalidad aplicable a los entes administrativos-territoriales.

En definitiva y como regla general, se suelen excluir determinados sujetos de la aplicación del procedimiento general, a saber: los entes públicos, así como las entidades financieras (entidades de seguros, de crédito y de inversión), que hay que acudir a su legislación específica para saber cómo actuar, además de otra serie de normas que nacen y se configuran por circunstancias excepcionales que originan la conformación de procedimientos paraconcursales paralelos al procedimiento concursal general. La pregunta que se plantea es si no supone esto una dispersión legislativa y, un atentado contra la seguridad jurídica. La respuesta es negativa ya que el basamento se haya en la especialidad, el problema se agrava cuando esa especialidad se generaliza que, cabalmente, el procedimiento excepcional se convierte en general y el procedimiento común queda residualmente para pequeñas empresas.

Al otro lado del Atlántico, hallamos la legislación de Chile (del año 1982, ex art. 41), donde se precisa que el deudor que ejerza una actividad comercial, industrial, minera o agrícola, deberá solicitar la declaración de su quiebra antes de que transcurran quince días contados desde la fecha en que haya cesado en el pago de una obligación mercantil. Derivado del ámbito subjetivo de aplicación podemos inferir e interpretar, en sentido extenso, que entrarían todos los sujetos dentro del ámbito de actuación de esta Ley, sin distinción de ningún tipo, si bien es cierto, que se han dictado numerosa y variada normativa de carácter público-administrativo para resolver la situación de dificultades económico-financieras de determinadas empresas. Estas medidas que han sido múltiples integraría el arsenal que compone el Derecho paraconcursal, que se aleja -como no- de lo establecido en el régimen general. Aquí se estaría conjugando e interrelacionado la legislación de la crisis empresarial.

Por lo que atañe a Venezuela (1955), cabe apuntar que no se establecen, in principio, en la legislación venezolana procedimientos paraconcursales, toda vez que las distinciones respecto a los diversos procedimientos de insolvencia vienen dados por las especialidades de los procedimientos contemplados en el Código de 
Comercio. Aunque es cierto que derivado de determinadas circunstancias de crisis y excepcionalidad, -es consabido- que el gobierno podrá dictar normas particulares no recopiladas ni sistematizadas sobre la materia en función del caso concreto, con lo cual estaríamos ante un procedimiento paraconcursal.

Por su parte, en el Derecho Colombiano, en especial el viejo y derogado del año (1999), se derivaban a lo largo del articulado diversos preceptos donde se deja al margen de actuación por parte de la Ley a los entes públicos y de Derecho administrativo. Ejemplo es el artículo 27, al determinar el plazo para la celebración de los acuerdos. Los acuerdos deberán celebrarse dentro de los cuatro (4) meses contados a partir de la fecha en que queden definidos los derechos de voto, mediante decisión del promotor o mediante la ejecutoria de la providencia de la Superintendencia de Sociedades que resuelva las objeciones que llegaren a presentarse. En el caso de las empresas públicas del orden nacional, se dará aplicación a lo dispuesto en el artículo 52 de la Ley 489 de 1989; y en el caso de las empresas públicas que no sean del orden nacional, se dará aplicación a lo dispuesto en las respectivas ordenanzas y acuerdos. Así, dentro del mismo ámbito de actuación de la ley 550 en su Título V se disciplinaba "de la reestructuración de pasivos de las entidades territoriales" (1999, art. 58).

Todo ello nos da muestra de la existencia de una legislación paraconcursal coetánea a la normativa genérica que supone la Ley 550, no de manera muy alejada siguen coexistiendo con la actual legislación (2006) procedimientos paraconcursales y la legislación general.

En similar línea, el Derecho mejicano del año (2000), No contempla procedimientos paraconcursales, aunque bien es cierto que este texto legislativo viene a reglamentar supuestos/procedimientos especiales como son "De los concursos mercantiles de comerciantes que prestan servicios públicos concesionados" y los somete a concurso mercantil supeditado a la norma común. Incluso es más, esta Ley mejicana que reseñamos trata "Del concurso Mercantil de las Instituciones de Crédito", al decir en su art. 245.- El concurso mercantil de las instituciones de crédito se regirá por lo previsto en esta Ley, en lo que no se oponga a las disposiciones especiales que les sean aplicables. Por su parte, el art. 246.- Sólo podrán demandar la declaración de concurso mercantil de una institución de crédito el Instituto para la Protección del Ahorro Bancario o la Comisión Nacional Bancaria y de Valores en términos de las disposiciones aplicables. Se infiere, por tanto, el sometimiento a la legislación común excepto en aquellas especialidades impuestas por las normas generales. La legislación mejicana sigue lo reglamentado en el Derecho continental europeo.

Dentro de este alcance de actuación, cabe decir que en la Legislación peruana del año (2001), dentro del glosario de términos que la propia Ley establece menciona el TUPA.- Texto Único de Procedimientos Administrativos del INDECOPI. Este texto viene a complementar la Ley general del sistema de reestructuración financiera, configurándose así como la legislación paraconcursal añadida a esta 
normativa genérica. Lo anterior se complementa con el ámbito de exclusión de la normativa aplicable, así en su artículo $2^{\circ}$.- Ámbito de aplicación de la norma y aplicación preferente. $2.1 \mathrm{La}$ Ley se aplica obligatoriamente a los procedimientos concursales de los deudores que se encuentren domiciliados en el país, sin admitir pacto en contrario. No son oponibles para efectos concursales los acuerdos privados relativos a la sustracción de ley y jurisdicción peruana. 2.2 No se encuentran comprendidas en la Ley, como deudores, las administradoras privadas de fondos de pensiones, las personas que forman parte del sistema financiero o del sistema de seguros, y aquéllas a las cuales la Comisión Nacional Supervisora de Empresas y Valores - CONASEV otorga autorización de funcionamiento. Asimismo, tampoco se encuentra comprendidas en la Ley los patrimonios autónomos, salvo las sociedades conyugales y sucesiones indivisas. 2.3 En la tramitación y resolución de los procedimientos concursales, las disposiciones previstas en la Ley se aplicarán preferentemente a cualquier otra norma que contenga disposiciones distintas.

Podemos vislumbrar que en la legislación peruana se excluye expresamente determinados entes públicos y entes pertenecientes al mercado financieros (aseguradoras y bancos, entre otras) del procedimiento general. La normativa reglamentadora de la insolvencia de estos sujetos constituye la legislación paraconcursal.

En otro orden de cosas, la legislación más reciente de Brasil del año (2005, ex art.2) es el reflejo de querer dejar al margen con su reciente Ley de recuperación de empresas y quiebra al Derecho paraconcursal, aunque se excluye de su ámbito de aplicación a los entes públicos, las instituciones financieras públicas o privadas, cooperativas de crédito, consorcios, sociedades/operadores en el plano asistencial de la salud, sociedades de seguros, sociedades de capitalización y otras entidades igualmente equiparadas a las anteriores. Ergo, hemos de acudir a diversa legislación especial que reglamenta la insolvencia de estos entes y que conforman el Derecho paraconcursal, así al Decreto Ley 73/1966 sobre el Sistema Nacional de Seguros Privados y Decreto 60459/1967 que desarrolla el anterior; Ley 5764 de política nacional de cooperativismo; Ley 7565/1986, Código brasileño de Aeronáutica; Ley 9656/1998, sobre planes y seguros privados de asistencia y de salud; Ley 109/2001, sobre providencia complementaria, entre otras. Esta legislación al igual que la Ley concursal mejicana encuentran gran influjo de lo reglamentado en las legislaciones europeas, si bien hay que advertir que no siempre se consigue por parte del legislador diferenciar claramente cuál es el ámbito especial y excluyente del ámbito común o general lo que da lugar a la introducción de un margen de discrecionalidad de los poderes administrativos no deseable en sistemas concursales que se precien.

IV.- Ejemplos paradigmáticos de coexistencia netamente diferenciada de procedimiento general y procedimientos paraconcursales (Italia e Inglaterra/ Argentina).

En este punto, resulta innumerable la legislación paraconcursal originada 
en Italia ${ }^{55}$ en torno a la ordenación de diversos aspectos conexos a la legislación concursal general, hasta el punto de existir monografías únicamente dedicadas a la materia del estudio de procedimientos paraconcursales ${ }^{56}$. En particular, cabe destacar respecto a la legislación de crisis de los entes de crédito: Decreto Legislativo de 1 de septiembre de 1993, n³85 (GU de 30 de septiembre 1993, n²30); Decreto Legislativo de 4 de agosto de 1999, n²33 (GU 28 de septiembre de 1999, n²28). Respecto a las aseguradoras, Decreto Legislativo de 17 de marzo de 1995, nº175 (GU 18 de marzo de $\left.1995, \mathrm{n}^{\circ} 114\right)$.

Considérese que incluso la ley ilustrada en la disciplina de la administración extraordinaria de la gran empresa en estado de insolvencia del año (1999), que engloba a la crisis de los grupos de empresa, aunque se remita constantemente a la ley de quiebras o Real Decreto del año (1942), ésta puede ser considerada como un procedimiento paraconcursal, toda vez que nace por una necesidad concreta y precisa traducida en el Decreto Legislativo 8 julio de 1999, n. 270. Luego, la legislación concursal general (1942) coexiste con múltiple legislación paraconcursal.

Otro ejemplo destacado de la coexistencia del régimen general de los procedimientos concursales con respecto al Derecho paraconcursal lo encontramos en Inglaterra. Junto a la disciplina de la Insolvency Act de 1986 y de 2000, existen en Inglaterra normas específicas para determinados sujetos que difieren del régimen general dispuesto en las anteriores normas generales. Así nos hallamos disposiciones relativas a la Financial Services Act de 1986; Banking Act de 1987, Financial Market and Insolvency Regulations 1996. Pero junto a esta reglamentación específica, también nos encontramos con otra de Derecho público-Administrativo, que son determinados acuerdos entre las empresas insolventes y sus acreedores con intervención del gobierno inglés para reflotar dichas empresas por determinadas circunstancias de corte económico, así: Informal Moratorium; Unofficial Receivership; Informal Reconstruction Scheme reglamentado en Transfer of Undertakings (Protection of Employment) Regulations 1987; The London Approach ${ }^{57}$.Todo este rosario que se halla al margen de la legislación genérica vendrá a constituir el arco de actuación del Derecho paraconcursal.

Además, no debemos desconocer tampoco el hecho que en la misma legislación general, se hacen constantes referencias a otras normativas en base a la particularidad del sujeto implicado dentro del procedimiento de insolvencia, a modo de ejemplo, "it is an insurance company within the meaning of the Insurance Companies Act 1982, (b) it is an authorised institution or former authorised institution

\footnotetext{
${ }^{55} \mathrm{Al}$ respecto, véase a FALCONE, G. "Modificaciones en la normativa concursal italiana y crisis económica de la Compañía aérea 'Alitalia'". Nº.10. Revista de Derecho Concursal y Paraconcursal, 2009.pp. 485 a 487.

${ }^{56}$ Cfr., in totum, SPARANO, Vicenzo y SPARANO, Biancamaria. Leggi Collegate alla Legge Fallimentare. Padova: Cedam, 2000.

${ }^{57}$ Véase para más información CANDELARIO MACÍAS, I. II Diritto Concorsuale in Europa. Padova: Cedam, 1999. pp.72 y ss.
} 
within the meaning of the Banking Act 1987, (c) it is a party to a market contract, a money market contract or a related contract or any of its property is subject to a market charge, a money market charge or a system-charge, or(d) it is a participant (within the meaning of the settlement finality regulations) or any of its property is subject to a collateral security charge (within the meaning of those regulations)". Luego, las entidades financieras como regla general presentan particularidades respecto a la legislación común.

En el Derecho latinoamericano una muestra de la coexistencia de ambas legislaciones se encuentra en la legislación argentina, puesto que No son susceptibles de ser declaradas en concurso, las personas reguladas por leyes específicas y determinadas $\mathrm{N}^{\circ} \mathrm{s} .20 .091,20.321$ y 24.241 , al mismo tiempo que las excluidas por leyes especiales. Del tenor literal de las normas se excluyen determinados entes y sujetos que nos vienen a delimitar la existencia de un Derecho paraconcursal complementario al régimen general disciplinado en la Ley que comentamos. Los sujetos que se excluyen forman parte del sistema financiero (aseguradoras, bancos y Mercado de Valores) y otras de especial interés para el legislador de este país, por ejemplo, Ley 25284, de régimen especial de administración de las entidades deportivas con dificultades económicas, fideicomiso de administración con control judicial; Ley 25561, de emergencia pública y reforma del régimen cambiario, entre otras.

Notése que bajo este contexto y marco de actuación económica, en la Argentina, han sido múltiples las normas y leyes de carácter paraconcursal habidas en los últimos años; siendo el alcance del Derecho concursal, propiamente dicho, cada vez más limitado.

\section{V. - Conclusiones.}

A la pregunta que nos sirve de título de la exposición no podemos responder con caracteres apriorísticos sin conocer la cultura jurídica y económica de un país. Cierto es que revisando y observando los sistemas concursales en los diferentes países sean europeos como latinoamericanos presentan una línea de coexistencia o cohabitación entre ambos modos de regular la crisis. Si nos detenemos en Italia, aunque no sea ejemplar en sus resultados prácticos, perviven ambos modos de afrontar la crisis empresarial. Si acudimos a los sistemas latinoamericanos y nos centramos en el Perú con un procedimiento fuertemente administrativizado los resultados tampoco son mucho mejores. Ahora bien, las recientes reformas concursales han intentado alejarse de los denominados procedimientos paraconcursales, sea España o Méjico, pero tampoco en el tiempo que llevan funcionando y extendiendo su manto logran el éxito buscado, toda vez que la excepcionalidad del caso supera a lo general. Si nos detenemos en los procedimientos paraconcursales híbridos en las legislaciones de los diferentes países podemos inferir lo que sigue: 
Primero que las legislaciones concursales más recientes en el tiempo (Alemania, Brasil, España, Méjico y Portugal) tienden a centralizar la normativa de insolvencia del deudor, sin desconocer las especialidades que presentan determinados sujetos económicos. En tal sentido, las empresas del sector financiero y demás entes de carácter público suelen estar supeditadas a una estrecha vigilancia y supervisión por parte de la Administración y de los órganos centrales administrativos de ordenación, y con la mirada puesta en la tutela de los intereses generales representados tanto por la propia seguridad del sistema financiero, como por los derechos e intereses de los asegurados, inversores, depositantes, ahorradores y, en general, de los clientes de estas empresas. Es lógico pensar que el legislador pretenda o tienda a excluir a estos agentes del sistema general o, inclusive, si se contienen bajo el marco de actuación del régimen general puedan traslucirse determinadas particularidades en su regulación.

Así pues y en consonancia con tales intereses generales, el Ordenamiento jurídico posibilita medidas variadas para tutelarlos en los supuestos de crisis empresarial, entre otras, la intervención de la empresa, la liquidación intervenida o la liquidación administrativa forzosa, pero no, exclusivamente, para atender supuestos de crisis empresariales, sino en adecuación a otros supuestos diferentes, que se encuadran dentro del término genérico Derecho paraconcursal, que están al margen del Derecho concursal general por ordenarse y encontrarse fuera de la Ley general en otras de carácter extraordinario.

Normalmente, las legislaciones concursales en su ámbito de aplicación (presupuesto subjetivo) suele excluir ya a determinados sujetos de la aplicación genérica de la Ley. Así, los entes públicos y administrativos suelen reglamentarse en otra legislación que conforma lo que hemos denominado procedimientos paraconcursales. Incluso en el Derecho uniforme y la insolvencia transnacional, el Reglamento (CE) 1346/2000 sobre procedimientos de insolvencia comunitaria, suele excluir de la aplicación genérica de la norma no sólo a aquellos entes de Derecho público, sino a las entidades financieras y éste es el planteamiento o fundamento seguido y reconocido en la mayoría de legislaciones de Derecho concursal europeo, y aunque la legislación española no lo menciona expresamente en su presupuesto subjetivo respecto a los entes financieros, es bien cierto que se reconocen las especialidades de estos sujetos (ex Disposición Adicional 2a).

Destacar, a su vez, que son escasas las legislaciones que dentro de la legislación general contemplen la legislación especial aplicable a determinados sujetos, entre estas normativas, nos encontramos con la legislación brasileña que sistemáticamente al igual que la legislación española dentro del marco general señala cuáles son las leyes de carácter especial, aunque esto puede plantear problemas de técnica legislativa como sucede en España al tener que reformar la norma en la disposición determinada para introducir qué se considera cómo legislación especial. 
Agregado a lo anterior y en lo que hace al Derecho concursal español, justamente en períodos de crisis se hace más evidente la extensión de los procedimientos paraconcursales y-seguidamente- se plantea el interrogante de si dicha extensión desvirtúa la verdadera funcionalidad atribuida al Derecho de la crisis precisamente por la situación de crisis económica.

Añadir, a su vez, que existen legislaciones donde cohabitan tanto la legislación paraconcursal como la concursal común o genérica (Argentina, Italia e Inglaterra). Estas reglas se interrelacionan haciéndose continuas remisiones de la legislación general a la especial y a la inversa, también cabe apuntar y reconocer que la técnica legal no es lo más recomendable.

Finalmente, ha de señalarse que la opción de política legislativa de escoger un sistema u otro (administrativo o judicial) es más honda por sus repercusiones de altura jurídica, que la técnica jurídica de incluir o excluir a determinados sujetos del ámbito de actuación de la norma general. El hecho qué países como Francia hayan desjudicializado su sistema concursal para ser administrativo respondía a la realización de la finalidad de prevención de la situación de insolvencia; en cambio, la judicialización y atribución de mayores poderes al órgano jurisdiccional en España responde al criterio de seguridad jurídica y de tutela del crédito. Aquellos países que se hallan en un intermedio de coexistencia de procedimientos de versante administrativo y judicial han intentado e intentarán buscar la mejor de las soluciones a la situación de insolvencia y un buen ejemplo es el sistema inglés donde la profesionalización y carácter experto de sus administradores hace posible dicha conciliación.

\section{VI. - Bibliografía destacada.}

-AA.VV. Régimen de concursos y quiebras: Ley 24,522: complementada con leyes 20.091, 20.321, 21.526. Buenos Aires: Astrea, 2004.

-AA.VV. Lei de recuperaçao de empresas e falência. Sâo Paolo: Editora Saraiva, 2005.

-BONFATTI, S. La legislazione concorsuale in Europa: esperienze a confronto. Milano: Giuffrè, 2004.

-CANDELARIO, I. Il Diritto Concorsuale in Europa. Padova: Cedam (Italia), 2001.

-CANDELARIO, I. Gestión de riesgos: impacto de la Ley Concursal en la compañía asegurador y el seguro de crédito. Madrid: La Ley/Wolters Kluwer, 2009.

-DEL GUAYO CASTIELLA, Iñigo. Sector público empresarial e instituciones paraconcursales. Madrid: Marcial Pons, 2004. p.227.

-FLINT, Pinkas. Reflotamiento. Aspectos económicos y financieros aplicables a la gestión de empresas en crisis. 2. Tomos. Lima: Grijley, 2004. 
-JUNYENT BAS, Francisco. Ley de concursos y quiebras: comentada. 2 Vóls.Buenos Aires: Depalma, 2003.

-LÓPEZ-BARAJAS PEREA, I. y GÓMEZ-SANCHA TRUEBA, I."Especialidades del concurso de las entidades financieras tras la nueva Ley Concursal". $N^{\circ} .254$. Revista de Derecho Mercantil, 2004.pp.1544 y ss.

-MELÉNDEZ HUELIN, O. "Derecho concursal y normativa contable del Banco de España: provisiones por insolvencia y alternativas al concurso de acreedores". $\mathrm{N}^{\circ} .10$. Revista de Derecho Concursal y Paraconcursal, 2009.pp. 241 a 260.

-PEROCHON, Frco. Entreprises en difficulté: instruments de crédit et de paiement. París: LGDJ Monrchrestien, 2003.

-PESUCCI, S. L'amministrazione controllata. Milano: Giuffrè, 2004.

-PRIEGO PÉREZ, J."Tratamiento Jurídico de las crisis bancarias". En Lecciones de Derecho Bancario y Bursátil, 2001.pp. 95 y ss.

-SPARANO, Vicenzo y SPARANO, Biancamaria. Leggi Collegate alla Legge Fallimentare. Padova: Cedam, 2000. 